\title{
Cumplimiento de las obligaciones internacionales en materia de reparación integral por el Consejo de Estado colombiano
}

\section{Compliance with international obligations in the matter of integral reparation by the Colombian State Council}

DOI: http://dx.doi.org/10.17981/juridcuc.13.1.2017.7

Artículo de reflexión. Fecha de recepción: 13/07/2017 Fecha de aceptación: 11/09/2017

\section{Luisa Fernanda Castañeda Quintana ${ }^{1}$ \\ Universidad Libre (Colombia) \\ lu_castaneda@yahoo.com}

\author{
Heidy Rojas Duque ${ }^{2}$ \\ Universidad Libre (Colombia) \\ heydi.rojas.duque@gmail.com
}

Para citar este artículo:

Castañeda, L. y Rojas, H. (2017). Cumplimiento de las obligaciones internacionales en materia de reparación integral por el Consejo de Estado colombiano. JURÍDICAS CUC, vol. 13, no. 1, pp. 147 182. DOI: http://dx.doi.org/10.17981/juridcuc.13.1.2017.7

\section{Resumen}

La reparación integral constituye un pilar fundamental en el marco de los derechos humanos, toda vez que promueve la reivindicación del ejercicio de los mismos. Es por esto que la Corte Interamericana ha desarrollado un precedente jurisprudencial ejemplar en materia de reparación con el fin de devolver la dignidad a las víctimas y evitar que los hechos se repitan, creando en los Estados cargas impositivas que lleven a desplegar acciones y omisiones tendientes a garantizar el libre y pleno ejercicio de derechos.

\footnotetext{
1 Abogada. Magíster en Derecho Administrativo. Consultora e investigadora en Derechos Humanos, Responsabilidad Social Empresarial y derechos étnico-territoriales. Litigante ante el Sistema Universal e Interamericano de Derechos Humanos.

${ }^{2}$ Abogada y filósofa de la Universidad Libre de Colombia. Litigante e investigadora en Derechos Humanos y Derecho Constitucional.
}

- The author; licensee Universidad de la Costa - CUC. 
Las cortes nacionales tienen una gran responsabilidad en el cumplimiento de esa orden, lo que las lleva a adoptar esos estándares con el fin de parar y/o evitar la vulneración de derechos y así cumplir con las obligaciones internacionales.

\section{Palabras clave}

Derechos humanos, reparación integral, Corte Interamericana, Colombia, Consejo de Estado, obligaciones internacionales

\section{Abstract}

The integral reparation constitutes a fundamental pillar in the human rights framework, since it promotes and protect the Human Rights; therefore, the Inter-American Court of Human Rights has developed a legal precedent in the topic above mentioned in order to restore the victim's dignity and to improve the recurrence of similar cases. The Inter-American Court levy the member States to develop actions or omissions that tend to guarantee the free and complete exercise of rights in general. The Colombian national courts have a great responsibility in complying with that order, which implements the standards in order to stop and or avoid violation of rights and thus comply with international obligations.

Key words

Human Rights, Integral Reparation, Inter-American Court of Human Rights, Colombia, Colombian Council of State, and International Obligations.

\section{INTRODUCCIÓN}

Debido a las graves violaciones de derechos humanos que se han dado en varios países de Latinoamérica, entre esos Colombia, el Sistema Interamericano de Derechos Humanos (SIDH), con mucha más fuerza la Corte Interamericana de Derechos Humanos (CorteIDH), ha adoptado decisiones con un fuerte contenido sobre los derechos violados y las reparaciones integrales fundamentada en las obligaciones internacionales que se derivan de la Convención Americana sobre Derechos Humanos (CADH). 
En ese sentido, la reparación integral ha tomado fuerza en el marco del Derecho internacional de derechos humanos para ser aplicada en tribunales internacionales y procesos de justicia transicional en los que se habla de verdad, justicia y reparación. Eso lleva a que reparar sea una obligación internacional que debe ser cumplida por los Estados, la cual tiene por objetivo compensar los daños causados producto de las violaciones de los derechos humanos. De ahí la importancia de que sea adoptado por los tribunales nacionales, siendo la víctima el eje de la protección con el fin de evitar la revictimización, preservar la memoria histórica y garantizar la dignidad.

Por lo anterior surge la pregunta que guía esta investigación: ¿está el Estado colombiano, a través del Consejo de Estado, cumpliendo con las obligaciones internacionales en materia de reparación integral? El Estado colombiano, si bien ha tenido una constante evolución legal y jurisprudencial en aras de la protección de los derechos humanos al fortalecer sus políticas y entidades, aún no ha logrado dar un óptimo cumplimiento a las obligaciones internacionales sobre reparación integral. Lo anterior se refleja en los aspectos que difieren en las sentencias de reparación integral proferidas por el Consejo de Estado y la Corte Interamericana, siendo esta última más completa y garantista en sus decisiones. Esta hipótesis puede sostenerse con el estudio de casos que se expondrán más adelante.

En esta investigación se utilizarán métodos precisos, como el método descriptivo, porque busca especificar propiedades importantes de personas, grupos y comunidades, en este caso, la forma cómo se están reparando a las víctimas de violaciones de derechos humanos. También es sociojurídica, pues busca estudiar el derecho en la vida social y en su práctica material. El método de investigación para llegar al objetivo general es dialéctico porque es necesario no estudiar los hechos a partir de condiciones generales, sino de hechos y fenómenos concretos (jurisprudencia y fallos de sentencias que deciden sobre cómo reparar a las víctimas y contrastarlo con la realidad).

El siguiente artículo ha sido estructurado de la siguiente manera: en una primera parte se expone y analiza el desarrollo jurisprudencial en materia de reparación integral por parte de la Corte Interamericana desde su entrada en funcionamiento; en la 
segunda parte, se relacionan casos, desde el año 2007, en los que el Consejo de Estado (CE) ha empezado a aplicar los estándares internacionales de reparación integral; y en una sección posterior, se finaliza con algunas reflexiones sobre el nivel de cumplimiento de las obligaciones internacionales por parte del Estado colombiano a través del Consejo de Estado sobre reparación integral cuando se trata de violaciones de derechos humanos.

\section{DESARROLLO}

\section{Las medidas de reparación adoptadas por la} Corte Interamericana de Derechos Humanos

La Corte Interamericana de Derechos Humanos a lo largo del desarrollo jurisprudencial ha evolucionado en el reconocimiento de medidas de reparación, es así que ha sentado un precedente jurisprudencial interamericano sólido sobre reparación integral que ha sido acogido por tribunales nacionales.

En ese sentido, la Convención Americana sobre Derechos Humanos (CADH) reconoce en el artículo 63 el derecho a la reparación integral cuando se cause un daño producto de una violación de derechos humanos, es decir, una violación a una obligación internacional. El artículo dice lo siguiente:

Artículo 63.1. Cuando decida que hubo violación de un derecho olibertad protegido en esta Convención, la Corte dispondrá que se garantice al lesionado en el goce de su derecho o libertad conculcados. Dispondrá, asimismo, si ello fuera procedente, que se reparen las consecuencias de la medida o situación que ha configurado la vulneración de esos derechos y el pago de una justa indemnización a la parte lesionada.

A partir de esta disposición es que la CorteIDH ha proferido en sus sentencias el reconocimiento de la reparación integral, la cual está compuesta por medidas que buscan resarcir el daño causado a las víctimas, tales como: (i) restitución, (ii) medidas de rehabilitación, (iii) medidas de satisfacción, (iv) garantías de no repetición e (vi) indemnización por los daños materiales e inmateriales.

Las reparaciones tienen como objetivo revertir ese daño causado, en ese sentido, la CorteIDH (2006) ha sostenido que:

Las reparaciones, como el término lo indica, consisten en las medidas que tienden a hacer desaparecer los efectos de las violaciones cometidas. 
$\mathrm{Su}$ naturaleza y su monto dependen del daño ocasionado en los planos tanto material como inmaterial. Las reparaciones no pueden implicar ni enriquecimiento ni empobrecimiento para la víctima o sus sucesores $^{3}$.

La reparación, en principio, busca obtener una restitución plena del derecho, es decir, volver las cosas al estado anterior ${ }^{4}$. Sin embargo, cuando se trata de violaciones de derechos humanos, muchas veces esa restitución no se logra porque nos enfrentamos a masacres donde el máximo derecho fue vulnerado, la vida, situación que no es sujeta de ninguna medida para restablecerlo. En relación con casos como privación de la libertad, derechos políticos, propiedad, entre otros, la restitución del derecho es viable. En ese sentido, en los casos en los que no es posible revertir el hecho causante de la violación, se procede a determinar otras medidas de reparación; esto no significa que en los otros casos no haya reparación integral, lo que implica esto, es que la restitución no aplica y se procede a determinar otras medidas, como la indemnizatoria.

Cuando se refieren a la indemnización, se habla de la compensación económica dada a las víctimas por el daño material e inmaterial. El Sistema Interamericano de Derechos Humanos (SIDH), al momento de tasar la indemnización, calcula el daño material, entendido como: "la pérdida o detrimento de los ingresos de las víctimas, los gastos efectuados con motivo de los hechos y las consecuencias de carácter pecuniario causadas por los hechos del caso sub judice" ${ }^{5}$, es decir, el daño emergente y lucro cesante. Igualmente, se toma el daño inmaterial o moral, el cual ha sido definido por la Corte Interamericana como:

El daño inmaterial [que] puede comprender tanto los sufrimientos y las aflicciones causados por la violación como el menoscabo de valores muy significativos para las personas y cualquier alteración, de carácter no pecuniario, en las condiciones de existencia de las víctimas ${ }^{6}$.

\footnotetext{
${ }^{3}$ Organización de Estados Americanos (OEA). CorteIDH. Caso Vargas Areco, 2006, párr. 142; caso Servellón García y otros, 2006, supra nota 3, párr. 163; y caso Almonacid Arellano y otros, 2006, párr. 137. ${ }^{4}$ OEA. CIDH. Caso Vargas Areco, 2006, párr. 141; caso Almonacid Arellano y otros, 2006, supra nota 15, párr. 136; y caso Servellón García y otros, 2006, párr. 162.

${ }^{5}$ OEA. CIDH. Caso del Penal Miguel Castro Castro Vs. Perú, 2006, párr. 423.

${ }^{6}$ OEA. CIDH. Caso Vargas Areco, 2006, párr. 149; caso Montero Aranguren y otros (Retén de Catia), supra nota 128, párr. 130; y caso Ximenes Lopes, 2006, párr. 227.
} 
En relación con las medidas de satisfacción y garantías de no repetición, son "aquellas medidas de satisfacción que buscan reparar el daño inmaterial, que no tienen alcance pecuniario, así como también dispondrá medidas de alcance o repercusión pública"7. Cuando se trata de casos de graves violaciones de derechos humanos, como masacres, desapariciones forzadas, ejecuciones extrajudiciales, torturas, etc., estas medidas tienen una gran importancia para las víctimas y familiares de las víctimas. Es en este aspecto que la CorteIDH es pionera y ha desarrollado medidas ejemplares para la conservación de la memoria histórica y reivindicación de la dignidad de las víctimas y familiares, además, han contribuido con la verdad y justicia. El tribunal ha ordenado a lo largo de su funcionamiento medidas como:

- Localizar los restos mortales de la víctima y entregarlos a sus familiares.

- Adecuar el derecho interno.

- Garantizar educación.

- Adoptar medidas de protección de los derechos humanos.

- Publicación de la sentencia en el diario oficial.

- Brindar atención médica y sicológica.

- Publicación de la sentencia en el diario oficial.

- Acto público de reconocimiento de su responsabilidad.

- Investigar y sancionar a los responsables de los hechos.

Por otra parte, el hecho de encontrar justicia en tribunales internacionales es muy importante para las víctimas cuando en sus países todos sus derechos fueron negados, especialmente, el derecho al acceso a la justicia. Es por esto que, obtener una sentencia en la que se reconozca que son víctimas y el Estado es responsable de las violaciones de sus derechos, ya es un avance muy importante para ellos, razón por la cual, la CorteIDH reitera siempre que la sentencia constituye per se una forma de reparación.

Es interesante analizar cómo la CorteIDH ha desarrollado su precedente en materia de reparación a lo largo de sus años, por lo que a continuación se relacionarán algunos casos que fueron seleccionados y organizados en intervalos de 5 a 8 años, con el propósito de demostrar cómo se fue desarrollando el concepto de

${ }^{7}$ OEA. CorteIDH. Caso Vargas Areco, 2006, párr. 152; caso Servellón García y otros, 2006, párr. 186; y caso Claude Reyes y otros, 2006, párr. 156. 
reparación integral en las decisiones de la CorteIDH y cómo este concepto influenció la forma de reparación por parte del Consejo de Estado colombiano, y así establecer si el mencionado tribunal cumple con la obligación internacional de reparar integralmente.

Tabla 1

Casos 1988 - 1995 .

\begin{tabular}{|c|c|}
\hline Caso & Reparación \\
\hline $\begin{array}{l}1988 \text { Velázquez } \\
\text { Rodríguez vs } \\
\text { Honduras }\end{array}$ & $\begin{array}{l}\text { - La corte fija una cantidad } 50.000 \text { lempiras como una } \\
\text { indemnización compensatoria del Estado a los familiares. } \\
\text { - Los hijos recibirán mensualmente los beneficios de este } \\
\text { fideicomiso, y al cumplir los veinticinco años de edad percibirán } \\
\text { la parte alícuota que les corresponda. }\end{array}$ \\
\hline $\begin{array}{l}1991 \\
\text { Caso } \\
\text { Aloeboetoe } \\
\text { y otros vs } \\
\text { Surinam }\end{array}$ & $\begin{array}{l}\text { - Fija un monto de } 453.102 \text { dólares como forma de reparar a las } \\
\text { víctimas. } \\
\text { - Dispone el establecimiento de dos fidecomisos y la creación de una } \\
\text { fundación y las actividades de la fundación no se pueden gravar. } \\
\text { - Ordena reabrir la escuela y dotarla de personal administrativo } \\
\text { para que funcione. }\end{array}$ \\
\hline $\begin{array}{c}1995 \\
\text { Neira Alegría y } \\
\text { otros vs Perú }\end{array}$ & $\begin{array}{l}\text { - Fija indemnizaciones debidas a los familiares de las víctimas por } \\
\text { un monto de } 154.040 .74 \text { dólares. } \\
\text { - Ordena el establecimiento de fidecomisos. } \\
\text { - Indemnización a favor de los menores de edad y la cónyuge. } \\
\text { - El Estado de Perú deberá hacer todo lo posible para localizar los } \\
\text { restos a las víctimas. }\end{array}$ \\
\hline $\begin{array}{l}1995 \\
\text { Caso Caballero } \\
\text { Delgado y } \\
\text { Santana vs } \\
\text { Colombia }\end{array}$ & $\begin{array}{l}\text { - Se fijan } 89.500 \text { pesos para las víctimas. } \\
\text { - Se fijan } 2000 \text { pesos por los gastos en los que han incurrido por las } \\
\text { gestiones a las autoridades colombianas. } \\
\text { El Estado colombiano se encuentra en la obligación de ayudar a } \\
\text { encontrar los restos familiares. }\end{array}$ \\
\hline
\end{tabular}

Fuente: Elaboración propia.

Como se puede observar en la tabla anterior, las reparaciones que se dan en el periodo de 1988-1995 son indemnizaciones que cubren los daños materiales e inmateriales. En los casos relacionados con la desaparición de las víctimas, la Corte ordenó al Estado encontrar los restos, esto como medidas de satisfacción. Sin embargo, hasta ese momento se nota una Corte muy tímida en materia de medidas de satisfacción y garantías de no repetición, pese a estudiar casos de graves violaciones de derechos humanos. No obstante, siguen siendo medidas de avanzada frente a las decisiones que para la época proferían los tribunales nacionales, los cuales solo se enfocaban en la indemnización económica. 
Tabla 2

Casos 1996-2001.

\begin{tabular}{|c|c|}
\hline Casos & Reparación \\
\hline $\begin{array}{c}1996 \\
\text { Caso } \\
\text { Garrido y } \\
\text { Baigorria vs } \\
\text { Argentina }\end{array}$ & $\begin{array}{l}\text { - Otorgar } 111.000 \text { dólares por indemnización a los } \\
\text { familiares. } \\
\text { - Buscar e identificar los dos hijos extramatrimoniales del } \\
\text { señor Raúl. } \\
\text { - Hacer pagos por los gastos que haya efectuado la } \\
\text { persona. } \\
\text { - Investigar los hechos que condujeron a la desaparición y } \\
\text { sancionar a los responsables. }\end{array}$ \\
\hline $\begin{array}{c}1997 \\
\text { Caso } \\
\text { Loayza } \\
\text { Tamayo vs } \\
\text { Perú }\end{array}$ & $\begin{array}{l}\text { - Reincorporar a la señora María Elena al servicio de } \\
\text { docente en instituciones públicas. } \\
\text { - Asegurar el pleno derecho a la jubilación desde que fue } \\
\text { detenida. } \\
\text { - Pagar indemnización por } 160.190 \text { dólares } \\
\text { - Adoptar medidas necesarias para que los Decretos- } \\
\text { Leyes } 25.475 \text { se adecuen a la Convención Americana. } \\
\text { - Investigar y sancionar a los responsables. }\end{array}$ \\
\hline $\begin{array}{c}1999 \\
\text { Caso del } \\
\text { Caracazo vs } \\
\text { Venezuela }\end{array}$ & $\begin{array}{l}\text { - Investigar y sancionar a los responsables. } \\
\text { Garantizar a los familiares de las víctimas y las víctimas } \\
\text { sobrevivientes la participación en todas las etapas de las } \\
\text { investigaciones. Los resultados de las investigaciones } \\
\text { deberán ser públicamente divulgados. } \\
\text { - Localizar, exhumar, identificar mediante el uso de } \\
\text { técnicas e instrumentos idóneos y entregar a sus } \\
\text { familiares los restos mortales de las dieciocho víctimas. } \\
\text { - Impartir formación a los grupos armados sobre derechos } \\
\text { humanos y el uso de la fuerza. } \\
\text { Otorgar indemnización por daños morales y materiales } \\
\text { por } 1.559 .800 \text { dólares. }\end{array}$ \\
\hline $\begin{array}{l}1999 \\
\text { Caso de los } \\
\text { "Niños de } \\
\text { la Calle" } \\
\text { (Villagrán } \\
\text { Morales y } \\
\text { otros) vs } \\
\text { Guatemala }\end{array}$ & $\begin{array}{l}\text { - Otorgar indemnización por daños morales y materiales. } \\
\text { Adecuar la normatividad interna con base en el artículo } \\
19 \text { de la CADH. } \\
\text { - Cubrir el traslado de los restos mortales de Henry } \\
\text { Giovanni Contreras y su posterior inhumación en el } \\
\text { lugar de elección de sus familiares. } \\
\text { - Designar un centro educativo con un nombre alusivo } \\
\text { a las jóvenes víctimas de este caso y colocar en dicho } \\
\text { centro una placa con los nombres. } \\
\text { - Investigar, juzgar y sancionar a los responsables y } \\
\text { adoptar en su derecho interno las disposiciones que } \\
\text { sean necesarias para asegurar el cumplimiento de esta } \\
\text { obligación. }\end{array}$ \\
\hline
\end{tabular}




\begin{tabular}{|c|c|}
\hline Casos & Reparación \\
\hline $\begin{array}{c}\text { 2000 } \\
\text { Caso } \\
\text { Trujillo } \\
\text { Oroza vs } \\
\text { Bolivia }\end{array}$ & $\begin{array}{l}\text { - Localizar los restos mortales de la víctima y entregarlos } \\
\text { a sus familiares. } \\
\text { - Tipificar el delito de desaparición forzada en su } \\
\text { jurisdicción interna. } \\
\text { - Adoptar medidas de protección de los derechos humanos } \\
\text { que aseguren el ejercicio libre y pleno de los derechos a } \\
\text { la vida, la libertad e integridad personal y la protección } \\
\text { y garantías judiciales. } \\
\text { - Dar oficialmente el nombre de José Carlos Trujillo } \\
\text { Oroza a un centro educativo de la ciudad de Santa Cruz. } \\
\text { - Otorgar indemnización por daños morales y materiales. } \\
\text { - Publicar la sentencia en el diario oficial. }\end{array}$ \\
\hline $\begin{array}{l}2000 \\
\text { Caso } \\
\text { Durand y } \\
\text { Ugarte vs } \\
\text { Perú }\end{array}$ & $\begin{array}{l}\text { - Brindar atención médica y sicológica. } \\
\text { - Publicar la sentencia en el diario oficial. } \\
\text { Emitir disculpas públicas y una ratificación de la } \\
\text { voluntad de que no volverán a ocurrir estos hechos. } \\
\text { - Investigar y sancionar a los responsables de los hechos. } \\
\text { Encontrar e identificar los cadáveres de Nolberto } \\
\text { Durand Ugarte y Gabriel Pablo Ugarte Rivera para } \\
\text { entregarlos a sus familiares. } \\
\text { - Otorgar indemnización por daños morales y materiales. }\end{array}$ \\
\hline $\begin{array}{c}2000 \\
\text { Caso } \\
\text { Bámaca } \\
\text { Velásquez } \\
\text { vs } \\
\text { Guatemala }\end{array}$ & $\begin{array}{l}\text { - Localizar los restos mortales de Efraín Bámaca } \\
\text { Velásquez y entregarlos a la familia. } \\
\text { - Investigar y sancionar a los responsables. } \\
\text { - Otorgar indemnización por daños morales y materiales. } \\
\text { - Publicar la sentencia en el diario oficial. } \\
\text { - Emitir Disculpas públicas. } \\
\text { - Adecuar el ordenamiento jurídico guatemalteco a las } \\
\text { normas internacionales de DDHH y DIH. }\end{array}$ \\
\hline $\begin{array}{c}2001 \\
\text { Caso } \\
\text { Barrios } \\
\text { Altos vs } \\
\text { Perú }\end{array}$ & $\begin{array}{l}\text { - Declarar que las leyes de amnistía } \mathrm{N}^{\circ} 26479 \text { y } \mathrm{N}^{\circ} 26492 \\
\text { son incompatibles con la CADH y, en consecuencia, } \\
\text { carecen de efectos jurídicos. } \\
\text { - Investigar y sancionar a los responsables. Los resultados } \\
\text { de las investigaciones deberán ser públicamente } \\
\text { divulgados. } \\
\text { - Brindar atención médica y sicológica. } \\
\text { - Otorgar indemnización por daños morales y materiales. } \\
\text { - Conceder becas y apoyos educativos para quienes deseen } \\
\text { adelantar estudios. } \\
\text { - Emitir disculpas públicas y una ratificación de la } \\
\text { voluntad de que no volverán a ocurrir estos hechos. } \\
\text { - Erigir un monumento. } \\
\text { Localizar a familiares de víctimas a través de medios de } \\
\text { difusión nacional. }\end{array}$ \\
\hline
\end{tabular}


En el cuadro anterior, las reparaciones que se ordenan entre el periodo de 1996 a 2001 van cambiando notoriamente. Se identifica una Corte que ordena medidas de satisfacción y garantías de no repetición que tienen un mayor impacto en la sociedad y para los Estados, lo que hace que se vuelvan casos emblemáticos con sanciones ejemplares que buscan que hechos como esos no se vuelvan a repetir. Entonces, para los Estados crea obligaciones adicionales a pagar por los daños a las víctimas, que en la práctica es la medida más fácil y la que más rápido cumplen los Estados. Asimismo, la Corte les ordena ofrecer disculpas públicas, lo cual tiene una trascendencia importante para las víctimas, además, decreta la construcción de monumentos, investigar y sancionar a los responsables, publicar la sentencia, declarar normas inconvencionales, adecuar el derecho interno, entregar los restos de las víctimas, brindar atención médica y siquiátrica, entre otras, las cuales contribuyen positivamente a la conservación de la memoria histórica y no revictimización.

Es de resaltar que los casos estudiados en ese periodo se tratan de graves violaciones de derechos humanos en un contexto de conflicto armado interno y/o dictaduras militares, política criminal de obstrucción de la justicia, uso de la fuerza, vinculación entre fuerza pública y paramilitares, estado de sitio, prácticas de persecución (acabar grupos insurgentes, rompimiento de la estructura social, cultural y familiar y suspensión de derechos), lo que llevó a la Corte a ser más creativa en materia de reparación, dado que por muchos años estos eran la clase de casos que siempre llegaban a la Corte, por lo que fue a través de su drástica jurisprudencia que se pudo ir recomponiendo estas situaciones de violaciones sistemáticas que ocurrieron en la década de los 70,80 y 90 .

La Corte en ese periodo dictó la primera sentencia en la que declaró la responsabilidad internacional del Estado por violación al proyecto de vida. Fue con el caso Loayza Tamayo vs Perú. Este nuevo concepto no corresponde a la misma definición que se le ha dado a lucro cesante y daño emergente, pues atiende a la 
[R]ealización futura individual de la persona que fue afectada, considerando y teniendo en cuenta factores como su actitud, vocación, aptitudes, circunstancias, potencialidades y aspiraciones, que pueden permitir fijarse en determinados logros y acceder a ellos, en otras palabras, se relaciona directamente con la realización personal y las probables opciones que tiene el sujeto de conducir su vida y lograr los objetivos que se ha o había propuesto (García, 2003, p. 340).

Según el doctrinante Sergio García Ramírez, este concepto va más allá de la pérdida de oportunidades que sufre la persona como consecuencia de la vulneración de la que ha sido víctima, por el contrario, es una afectación directa a la libertad del individuo, pues difícilmente una persona es libre "si carece de opciones para encaminar su existencia y llevarla a su natural culminación", y, en consecuencia, la violación por la que ha sido afectada "cambia drásticamente el curso de la vida que imponen circunstancias nuevas y adversas que modifican los planes y proyectos que una persona formula a la luz de las condiciones ordinarias en que se desenvuelve su existencia y de sus propias actitudes para llevarlas a cabo con probabilidad de éxito" (2003, p. 343).

La pretensión de la Corte es señalar y hacer notar que la alteración de vida ocurre de forma injusta y arbitraria, con violación a las normas vigentes y de confianza que el individuo deposita en órganos de poder público como el Estado, los cuales están obligados a proteger y bridar seguridad a todos sus asociados para que puedan ejercer libremente sus derechos y legítimos intereses.

Esta forma de daño se indemniza, pero no siempre se limita solo a una compensación económica, como se pudo observar en la tabla 2 , la reparación del daño moral ha incluido tratamientos de salud y sicológicos y becas de estudios superiores o universitarios con el fin de cubrir los costos de la carrera profesional que la víctima elija al igual que los gastos de manutención generados durante el periodo de estudios. ${ }^{8}$

\footnotetext{
${ }^{8}$ OEA. CorteIDH. Caso Cantoral Benavides, 2000; masacre de las Dos Erres, 2009; Mejía Idrovo, 2011; Furlán vs Argentina, 2012.
} 
Tabla 3

Casos 2002-2009.

\begin{tabular}{|c|c|}
\hline Casos & Reparación \\
\hline $\begin{array}{c}2002 \\
\text { Caso Hilaire, } \\
\text { Constantine } \\
\text { y Benjamin } \\
\text { y otros vs } \\
\text { Trinidad y } \\
\text { Tobago }\end{array}$ & $\begin{array}{l}\text { - Abstenerse de aplicar la Ley de Delitos contra la persona } \\
\text { de } 1925 \text { y, dentro de un plazo razonable, debe modificarla } \\
\text { adecuándola a las normas internacionales de DDHH. } \\
\text { - Abstenerse de ejecutar los resultados de los nuevos juicios. } \\
\text { - Otorgar indemnización por daños morales y materiales. } \\
\text { - Modificar las condiciones de su sistema carcelario para } \\
\text { adecuarlas a las normas internacionales aplicables a la } \\
\text { materia. }\end{array}$ \\
\hline $\begin{array}{c}2003 \\
\text { Caso Bulacio } \\
\text { vs Argentina }\end{array}$ & $\begin{array}{l}\text { - Investigar y sancionar a los responsables de los hechos. } \\
\text { en todas las etapas del proceso y los resultados deberán ser } \\
\text { públicamente divulgados. } \\
\text { - Publicar la sentencia en el diario oficial. } \\
\text { - Otorgar indemnización por daños morales y materiales. } \\
\text { - Garantizar que los hechos no se repitan adecuando el derecho } \\
\text { interno a los estándares internacionales de DDHH. }\end{array}$ \\
\hline $\begin{array}{c}2003 \\
\text { Caso Myrna } \\
\text { Mack Chang } \\
\text { vs Guatemala }\end{array}$ & $\begin{array}{l}\text { - Investigar y sancionar a los responsables de los hechos. } \\
\text { - Ofrecer disculpas públicas. } \\
\text { - } \text { aducar en DDHH y DIH a los miembros de las fuerzas } \\
\text { Otorgar una beca de estudios con el nombre de Myrna Mack } \\
\text { Chang. } \\
\text { - Dar el nombre de Myrna Mack Chang a una calle o plaza } \\
\text { reconocida en la Ciudad de Guatemala y colocar en el lugar } \\
\text { donde falleció una placa. } \\
\text { Otorgar indemnización por daños morales y materiales. }\end{array}$ \\
\hline $\begin{array}{c}2004 \\
\text { Caso 19 } \\
\text { comerciantes } \\
\text { vs Colombia }\end{array}$ & $\begin{array}{l}\text { - Investigar y sancionar a los responsables de los hechos. } \\
\text { - Buscar los restos de las víctimas y entregarlos a los familiares. } \\
\text { - Realizir un monumento en memoria de las víctimas. } \\
\text { responsabilidad internacional. } \\
\text { - Ofrecer tratamiento médico y psicológico. } \\
\text { - Garantizar condiciones para el regreso al país de familiares } \\
\text { que están en exilio. } \\
\text { - Otorgar indemnización por daños morales y materiales. } \\
\text { Publicar la sentencia en el diario oficial. }\end{array}$ \\
\hline
\end{tabular}


Cont...

Casos

\begin{tabular}{c}
\hline \\
\\
\\
\\
Caso masacre \\
Plan de \\
Sánchez vs \\
Guatemala
\end{tabular}

2004

Caso Tibi vs

Ecuador

2005

Caso de la

comunidad

Moiwana vs

Suriname
- Investigar y sancionar a los responsables de los hechos.

- Ofrecer disculpas públicas; éstas deben ser televisivas en español y en el idioma maya achí.

- Garantizar la no repetición mediante dotación de recursos para la memoria colectiva: mantenimiento y mejoras en la infraestructura de la capilla.

- Brindar tratamiento médico y psicológico.

- Otorgar vivienda a las víctimas sobrevivientes.

- Establecer un programa de desarrollo que incluya educación étnicolingüista con la dotación de personal docente capacitado en enseñanza intercultural, mejoramiento de vías, sistema de alcantarillado y suministro de agua potable, y establecimiento de un centro salud.

- Investigar y sancionar a los responsables de los hechos.

- Publicar la sentencia en el diario oficial.

- Realizar un acto público de reconocimiento de su responsabilidad internacional.

- Implementar un programa de educación en DDHH en el tratamiento de reclusos al ministerio público, policial y penitenciario, incluyendo al personal médico, psiquiátrico y psicológico.

- Otorgar indemnización por daños morales y materiales.

- Investigar y sancionar a los responsables de los hechos.

- Recuperar los restos de los miembros de la comunidad Moiwana y entregarlos.

- Adoptar todas las medidas legislativas y administrativas para asegurar a los miembros de la comunidad Moiwana su derecho de propiedad sobre los territorios tradicionales.

- Realizar un acto público de reconocimiento de su responsabilidad internacional.

- Fondo de desarrollo comunitario: otorgar indemnización por daños morales y materiales.

- Identificar el territorio tradicional de los miembros de la comunidad indígena Yakye Axa y entregárselos de manera gratuita.

2005

Caso

- Suministrar a la comunidad los bienes y servicios básicos para su subsistencia.

comunidad indígena

Yakye Axa vs Paraguay
- Crear un fondo destinado exclusivamente a la adquisición de las tierras.

- Adecuar el derecho interno para garantizar el efectivo goce del derecho a la propiedad de los miembros de los pueblos indígenas.

- Realizar un acto público de reconocimiento de su responsabilidad. 


\begin{tabular}{cll}
\hline & - Otorgar indemnización por daños materiales e inmateriales. \\
& - Investigar los hechos del caso, así como identificar y juzgar a los \\
& responsables. \\
$\mathbf{2 0 0 6}$ & - & Buscar, identificar y dar sepultura a las víctimas. \\
Caso de la & - Ofrecer tratamiento médico o psicológico. \\
masacre de & y exhabitantes destatales de seguridad para los familipiores de Pueblo Bello que decidan \\
Pueblo Bello & regresar. \\
vs Colombia & - Implementar un programa habitacional de vivienda adecuada. \\
& - Emitir una disculpa pública y el reconocimiento de \\
& responsabilidad internacional. \\
& Erigir un monumento. \\
& Publicar la sentencia.
\end{tabular}

\section{7 \\ Caso de la masacre de \\ La Rochela vs \\ Colombia}

- Otorgar indemnización por daños materiales e inmateriales.

- Investigar y sancionar a los responsables de los hechos.

- Garantizar que los funcionarios judiciales, fiscales, investigadores y demás operadores de justicia cuenten con un sistema de seguridad y protección adecuado.

- Brindar tratamiento médico y psicológico.

- Continuar programas de educación en derechos humanos dentro de las fuerzas armadas colombianas.

- Hacer un acto público de reconocimiento de su responsabilidad.

2007

- Publicar la sentencia en el diario oficial.

Caso

Zambrano

Vélez y otros vs Ecuador

- Adecuar el derecho interno en materia de estados de emergencia y suspensión de garantías con base en la $\mathrm{CADH}$.

- Implementar programas de educación en derechos humanos dirigidos a los miembros de las Fuerzas Armadas y Policía Nacional.

- Otorgar indemnización por daños materiales e inmateriales.

2007

Caso

Cantoral

Huamaní y

García Santa

Cruz vs Perú
- Otorgar indemnización por daños materiales e inmateriales.

- Investigar y sancionar a los responsables de los hechos.

- Publicar la sentencia en el diario oficial.

- Hacer un acto público de reconocimiento de su responsabilidad.

- Otorgar una beca en una institución pública peruana en beneficio de las víctimas y familiares.

- Brindar tratamiento psicológico y médico.

- Otorgar indemnización por daños materiales e inmateriales.

- Investigar y sancionar a los responsables de los hechos.

2008 - Publicar la sentencia en el diario oficial.

Caso del - Hacer un acto público de reconocimiento de su responsabilidad.

Penal Miguel - Brindar tratamiento psicológico y médico.

Castro vs - Entregar los restos de las víctimas.

Perú - Implementar programas de educación en DDHH dirigidos a agentes de las fuerzas de seguridad.

- Representación en el monumento denominado "El ojo que llora". 
Cont...

\begin{tabular}{|c|c|}
\hline Casos & Reparación \\
\hline $\begin{array}{c}2009 \\
\text { Caso Reverón } \\
\text { Trujillo vs } \\
\text { Venezuela }\end{array}$ & $\begin{array}{l}\text { Reincorporación al cargo o a un cargo similar al que } \\
\text { desempeñaba. } \\
\text { - Eliminar planilla en la que se establece que fue destituida. } \\
\text { - Aprobar un código de ética y adecuar su legislación interna a la } \\
\text { Convención Americana. } \\
\text { - Otorgar indemnización por daños materiales e inmateriales. }\end{array}$ \\
\hline $\begin{array}{l}\quad 2009 \\
\text { Caso Valle } \\
\text { Jaramillo } \\
\text { y otros vs } \\
\text { Colombia }\end{array}$ & $\begin{array}{l}\text { - Otorgar indemnización por daños materiales e inmateriales. } \\
\text { - Investigar y sancionar a los responsables de los hechos. } \\
\text { - Hablicar la sentencia en el diario oficial. } \\
\text { - Brindar tratamiento psicológico y médico. } \\
\text { - Realizar una placa en memoria de Jesús María Valle Jaramillo. } \\
\text { - Conferir beca para realizar estudios o capacitarse en un oficio. } \\
\text { - Garantizar la seguridad en caso que Carlos Jaramillo Correa } \\
\text { considere su retorno a Colombia. }\end{array}$ \\
\hline $\begin{array}{c}2009 \\
\text { Caso } \\
\text { González } \\
\text { y otros } \\
\text { (“Campo } \\
\text { Algodonero") } \\
\text { vs México }\end{array}$ & $\begin{array}{l}\text { - Otorgar indemnización por daños materiales e inmateriales } \\
\text { - Investigar y sancionar a los responsables de los hechos. } \\
\text { - Hublicar la sentencia en el diario oficial. } \\
\text { - Hacer un acto público de reconocimiento de su responsabilidad. } \\
\text { - Incluir una perspectiva de género: líneas de investigación } \\
\text { respecto a violencia sexual. } \\
\text { - Asegurarse que los órganos que participen en el procedimiento } \\
\text { de investigación cuenten con los recursos humanos y materiales } \\
\text { necesarios para desempeñar las tareas de manera adecuada. } \\
\text { - Levantar un monumento en memoria de las mujeres víctimas de } \\
\text { homicidio por razones de género en Ciudad Juárez. } \\
\text { - Implementar búsquedas de oficio y sin dilación alguna cuando se } \\
\text { presenten casos de desaparición. } \\
\text { - Crear una página electrónica que deberá actualizarse } \\
\text { permanentemente y contendrá la información personal necesaria } \\
\text { de todas las mujeres que continúan desaparecidas. }\end{array}$ \\
\hline
\end{tabular}

Fuente: Elaboración propia.

En el cuadro anterior, entre el periodo 2002-2009, la mayoría de reparaciones por violaciones a derechos humanos fueron consecuencia de masacres y vulneración de los derechos a comunidades indígenas.

En este periodo, la Corte dictó la primera sentencia (Caso González y otras "Campo Algodonero" vs México) en la que reconoció la Violencia Basada en Género como una práctica sistemática de violación de derechos humanos. En el mencionado caso ordenó incluir una perspectiva de género en las líneas de investigación respecto a violencia sexual; asegurar que los órganos que partici- 
pen en el procedimiento de investigación cuenten con los recursos humanos y materiales necesarios para desempeñar las tareas de manera adecuada; y levantar un monumento en memoria de las mujeres víctimas de homicidio por razones de género en Ciudad Juárez; además de otras medidas que ordena regularmente, como disculpas públicas. Este caso es muy importante porque imparte las medidas para que otros Estados las adopten internamente con el fin de parar las violaciones de los derechos de las mujeres.

Por otro lado, es un periodo en que la Corte emite varias sentencias sobre casos relacionados con comunidades indígenas, los cuales giran entorno al despojo de su territorio y desconocimiento del derecho a la consulta previa, lo que desencadenó múltiples violaciones de sus derechos, como la vida, el reconocimiento de una personalidad jurídica, su integridad personal, garantías judiciales y protección judicial. En estos casos se marcó un precedente muy importante en la materia que ha sido aplicado por la Corte Constitucional colombiana, tribunal que ha generado un gran avance en la protección de los derechos de las comunidades étnicas. Esto refleja la importancia del precedente que la CorteI$\mathrm{DH}$ construye, lo que significa que se cumple un objetivo y es que otros Estados que no hayan sido condenados apliquen la jurisprudencia para evitar que hechos similares se repitan. En ese orden de ideas, frente estos casos la sola sentencia constituyó una forma de reparación muy importante.

Además de ordenar la restitución de sus territorios; delimitar, demarcar y titular las tierras; y adecuar el derecho interno para garantizar a las comunidades su derecho de propiedad sobre los territorios tradicionales, la Corte ordenó al Estado implementar un fondo de desarrollo comunitario a través del cual se implemente un programa de desarrollo que provea servicios sociales básicos a los miembros de la comunidad cuando éstos regresen, por ejemplo, programas de salud, vivienda y educación de los miembros de la comunidad ${ }^{9}$. La Corte dispuso medidas de reparación colectivas por ser las comunidades indígenas sujeto de derechos colectivos que comparten un territorio.

\footnotetext{
${ }_{9}$ OEA. CorteIDH. Caso de la comunidad Moiwana vs Suriname, 2005; caso de la comunidad Mayagna (Sumo) Awas Tingni vs Nicaragua, 2001; Caso comunidad indígena Yakye Axa vs Paraguay, 2009 y Caso comunidad indígena Sawhoyamaxa vs Paraguay, 2006.
} 


\section{Tabla 4}

Casos 2010- 2015.

\begin{tabular}{|c|c|}
\hline Caso & Reparación \\
\hline $\begin{array}{c}2010 \\
\text { Caso } \\
\text { comunidad } \\
\text { indígena } \\
\text { Xákmok Kásek } \\
\text { vs Paraguay }\end{array}$ & $\begin{array}{l}\text { - Devolver a la comunidad las hectáreas reclamadas. } \\
\text { Decidir si procede la expropiación del territorio a favor de los } \\
\text { indígenas o buscar uno alterno. } \\
\text { - Hacer un acto público de reconocimiento de la responsabilidad } \\
\text { internacional del Estado. } \\
\text { - Publicar la sentencia en el diario oficial. } \\
\text { - Garantizar suministro de agua potable suficiente, atención } \\
\text { médica y psicosocial de todos los miembros de la comunidad, } \\
\text { atención médica especial a las mujeres embarazadas, entrega } \\
\text { de alimentos en calidad y cantidad suficientes, instalación de } \\
\text { servicios sanitarios adecuados y la dotación de materiales y } \\
\text { recursos de escuela para garantizar el acceso a la educación } \\
\text { procurando el respeto de las tradiciones culturales y las } \\
\text { lenguas propias. } \\
\text { - Establecer un puesto de salud permanente y con las medicinas } \\
\text { e insumos necesarios. } \\
\text { - Realizar un programa de registro y documentación. } \\
\text { - Otorgar indemnización por daños morales y materiales. } \\
\text { - Crear un fondo de desarrollo comunitario. }\end{array}$ \\
\hline $\begin{array}{l}\text { Caso Rosendo } \\
\text { Cantú y otra } \\
\text { vs México }\end{array}$ & $\begin{array}{l}\text { - Investigar y sancionar a los responsables de los hechos. Esas } \\
\text { investigaciones de violaciones sexuales se harán con base en el } \\
\text { Protocolo de Estambul y en las directrices de la Organización } \\
\text { Mundial de la Salud. } \\
\text { - Adoptar las reformas legislativas con base en los estándares } \\
\text { internacionales en la materia y de la Convención Americana } \\
\text { sobre Derechos Humanos. } \\
\text { - Adoptar la reforma al fuero militar sobre definición de } \\
\text { competencias. } \\
\text { - Hacer un acto público de reconocimiento de responsabilidad } \\
\text { internacional. } \\
\text { - Capacitar en derechos humanos a integrantes de las Fuerzas } \\
\text { Armadas y sobre la investigación de casos de violencia sexual } \\
\text { contra las mujeres dirigidos a los funcionarios federales y del } \\
\text { estado de Guerrero. } \\
\text { - Otorgar indemnización por daños morales y materiales. } \\
\text { Brindar tratamiento médico y psicológico a mujeres víctimas } \\
\text { de violencia sexual. } \\
\text { - Hacer campañas de concientización y sensibilización de la } \\
\text { población en general sobre la prohibición y los efectos de la } \\
\text { violencia y discriminación contra la mujer indígena. }\end{array}$ \\
\hline $\begin{array}{l}2011 \\
\text { Caso Vera } \\
\text { y otra vs } \\
\text { Ecuador }\end{array}$ & $\begin{array}{l}\text { - Adoptar las medidas necesarias para que la madre de Pedro } \\
\text { Miguel Vera pueda conocer lo sucedido a su hijo. } \\
\text { - Publicar la sentencia. } \\
\text { - Otorgar indemnización por daños morales y materiales. }\end{array}$ \\
\hline
\end{tabular}




\begin{tabular}{|c|c|}
\hline Caso & Reparación \\
\hline $\begin{array}{c}2011 \\
\text { Caso Torres } \\
\text { Millacura } \\
\text { y otros vs } \\
\text { Argentina }\end{array}$ & $\begin{array}{l}\text { - Otorgar indemnización por daños morales y materiales. } \\
\text { - Investigar y sancionar a los responsables de los hechos. } \\
\text { Continuar la búsqueda efectiva del paradero del señor Iván } \\
\text { Eladio Torres Millacura. } \\
\text { - Implementar un programa o curso obligatorio sobre derechos } \\
\text { humanos dirigido a la policía. } \\
\text { - Reintegrar al Fondo de Asistencia Legal a Víctimas de la } \\
\text { CorteIDH la suma erogada durante la tramitación del presente } \\
\text { caso. }\end{array}$ \\
\hline $\begin{array}{c}2011 \\
\text { Caso López } \\
\text { Mendoza vs } \\
\text { Venezuela }\end{array}$ & $\begin{array}{l}\text { - Asegurar, a través de los órganos competentes y particularmente } \\
\text { del Consejo Nacional Electoral, que las sanciones de } \\
\text { inhabilitación no constituyan impedimento para la postulación } \\
\text { del señor López Mendoza en el evento de que desee inscribirse } \\
\text { como candidato en procesos electorales a celebrarse con } \\
\text { posterioridad a la emisión de la sentencia. } \\
\text { - Dejar sin efecto las resoluciones de } 24 \text { de agosto de } 2005 \text { y } 26 \\
\text { de septiembre de } 2005 \text { emitidas por el Contralor General de la } \\
\text { República, mediante las cuales se declaró la inhabilitación para } \\
\text { el ejercicio de funciones públicas del señor López Mendoza. } \\
\text { - Publicar la sentencia en el diario oficial. } \\
\text { - Adecuar el artículo } 105 \text { de la Ley Orgánica de la Contraloría } \\
\text { General de la República y del Sistema Nacional de Control } \\
\text { Fiscal, de acuerdo con lo señalado en la sentencia } \\
\text { - Otorgar indemnización por daños morales y materiales. }\end{array}$ \\
\hline $\begin{array}{l}2012 \\
\text { Caso Atala Riffo } \\
\text { y niñas vs Chile }\end{array}$ & $\begin{array}{l}\text { - Brindar atención médica y psicológica o psiquiátrica gratuita y } \\
\text { de forma inmediata. } \\
\text { - Publicar la sentencia en el diario oficial y en un diario de amplia } \\
\text { circulación. } \\
\text { - Realizar un acto público de reconocimiento de responsabilidad. } \\
\text { - Continuar implementando programas de educación en DDHH } \\
\text { dirigidos a funcionarios públicos a nivel regional y nacional. } \\
\text { - Otorgar indemnización por daños morales y materiales. }\end{array}$ \\
\hline $\begin{array}{c}2012 \\
\text { Caso González } \\
\text { Medina y } \\
\text { familiares vs } \\
\text { República } \\
\text { Dominicana }\end{array}$ & $\begin{array}{l}\text { - Investigar y sancionar a los responsables de los hechos. } \\
\text { - Efectuar la búsqueda seria para determinar el paradero del } \\
\text { señor Narciso González Medina. } \\
\text { - Brindar atención médica y sicológica. } \\
\text { - Publicar la sentencia. } \\
\text { - Realizar un acto público de reconocimiento de su responsabilidad. } \\
\text { Golocar una placa conmemorativa en el Centro Cultural Narciso } \\
\text { - Realizar un documental audiovisual sobre la vida del señor } \\
\text { Narciso González Medina. } \\
\text { - Garantizar que la aplicación de las normas de su derecho } \\
\text { interno permitan realizar una investigación adecuada de la } \\
\text { desaparición forzada y, en caso de que éstas sean insuficientes, } \\
\text { realizar las reformas legislativas o adoptar las medidas de otro } \\
\text { carácter que sean necesarias para ello. } \\
\text { Otorgar indemnización por daños morales y materiales. }\end{array}$ \\
\hline
\end{tabular}


Cont...

\begin{tabular}{|c|c|}
\hline Caso & Reparación \\
\hline $\begin{array}{c}2012 \\
\text { Caso Fornerón } \\
\text { e hija vs } \\
\text { Argentina }\end{array}$ & $\begin{array}{l}\text { Establecer de manera inmediata un procedimiento orientado a } \\
\text { la efectiva vinculación entre el señor Fornerón y su hija. } \\
\text { - Verificar la conformidad a derecho de la conducta de } \\
\text { determinados funcionarios que intervinieron en los distintos } \\
\text { procesos internos y establecer las responsabilidades que } \\
\text { correspondan. } \\
\text { - Adoptar las medidas que sean necesarias para tipificar la } \\
\text { venta de niños y niñas } \\
\text { - Implementar un programa dirigido a operadores judiciales } \\
\text { de la Provincia de Entre Ríos respecto de niños y niñas que } \\
\text { contemple los estándares internacionales en derechos humanos } \\
\text { en materia de los derechos de los niños y niñas, y su interés } \\
\text { superior y el principio de no discriminación. } \\
\text { - Publicar la sentencia. } \\
\text { Otorgar indemnización por daños morales y materiales, así } \\
\text { como por el reintegro al Fondo de Asistencia Legal de Víctimas. }\end{array}$ \\
\hline $\begin{array}{c}2012 \\
\text { Caso pueblo } \\
\text { indígena } \\
\text { Kichwa de } \\
\text { Sarayaku vs } \\
\text { Ecuador }\end{array}$ & $\begin{array}{l}\text { - Neutralizar, desactivar y retirar la pentolita en superficie y } \\
\text { enterrada en el territorio del pueblo Sarayaku. } \\
\text { - Consultar al pueblo Sarayaku en el eventual caso que se } \\
\text { pretenda realizar alguna actividad o proyecto de extracción } \\
\text { de recursos naturales en su territorio, o plan de inversión o } \\
\text { desarrollo de cualquier otra índole que implique potenciales } \\
\text { afectaciones a su territorio. } \\
\text { - Adoptar las medidas necesarias para hacer efectivo el derecho } \\
\text { a la consulta previa de los pueblos y comunidades indígenas } \\
\text { y tribales, y modificar aquellas que impidan su pleno y libre } \\
\text { ejercicio, para lo cual debe asegurarse la participación de las } \\
\text { propias comunidades. } \\
\text { - Implementar programas sobre los estándares nacionales } \\
\text { e internacionales en derechos humanos de los pueblos y } \\
\text { comunidades indígenas, dirigidos a funcionarios militares, } \\
\text { policiales y judiciales. } \\
\text { - Realizar un acto público de reconocimiento de responsabilidad } \\
\text { internacional. } \\
\text { - Publicar la sentencia. } \\
\text { Otorgar indemnización por daños morales y materiales. }\end{array}$ \\
\hline $\begin{array}{c}2012 \\
\text { Caso Vélez } \\
\text { Restrepo y } \\
\text { familiares vs } \\
\text { Colombia }\end{array}$ & $\begin{array}{l}\text { - Garantizar las condiciones para que los miembros de la familia } \\
\text { Vélez Román regresen a residir a Colombia, en caso que así lo } \\
\text { decidan. } \\
\text { - Brindar atención médica. } \\
\text { - Publicar la sentencia. } \\
\text { - Adoptar programas sobre la protección del derecho a la libertad } \\
\text { de pensamiento y de expresión y de la labor que cumplen los } \\
\text { periodistas y comunicadores sociales. } \\
\text { - Adoptar otras medidas o acciones que permitan determinar } \\
\text { responsabilidades en el presente caso. } \\
\text { - Investigar y sancionar a los responsables de los hechos. } \\
\text { - Otorgar indemnización por daños morales y materiales. }\end{array}$ \\
\hline
\end{tabular}




\begin{tabular}{|c|c|}
\hline Caso & Reparación \\
\hline $\begin{array}{c}2012 \\
\text { Caso Artavia } \\
\text { Murillo y otros } \\
\text { ("fecundación } \\
\text { in vitro") vs } \\
\text { Costa Rica }\end{array}$ & $\begin{array}{l}\text { - Dejar sin efecto la prohibición de practicar la fecundación } \\
\text { in vitro y que las personas que deseen hacer uso de dicha } \\
\text { técnica de reproducción asistida puedan hacerlo sin encontrar } \\
\text { impedimento. } \\
\text { - Regular los aspectos que se consideren necesarios para su } \\
\text { implementación y establecer sistemas de inspección y control } \\
\text { de calidad de las instituciones o profesionales calificados que } \\
\text { desarrollen este tipo de técnica. } \\
\text { - El Seguro Social deberá incluir gradualmente la disponibilidad } \\
\text { dela fecundación in vitro dentro de sus programas y tratamientos } \\
\text { de infertilidad en su atención de salud. } \\
\text { - Otorgar gratuitamente el tratamiento psicológico a las víctimas. } \\
\text { - Publicar la sentencia en el diario oficial. } \\
\text { - Implementar programas de educación en DDHH, derechos } \\
\text { reproductivos y no discriminación dirigidos a funcionarios } \\
\text { judiciales. } \\
\text { Otorgar indemnización por daños morales y materiales. }\end{array}$ \\
\hline $\begin{array}{l}2013 \\
\text { Caso masacre } \\
\text { de Santo } \\
\text { Domingo vs } \\
\text { Colombia }\end{array}$ & $\begin{array}{l}\text { - Otorgar indemnización por daños morales y materiales. } \\
\text { - } \text { Brindar atención médica. } \\
\text { - Rublicar la sentencia en el diario oficial. } \\
\text { - Realizar un acto público de reconocimiento de su responsabilidad. }\end{array}$ \\
\hline $\begin{array}{l}2013 \\
\text { Caso de las } \\
\text { comunidades } \\
\text { afro- } \\
\text { descendientes } \\
\text { desplazadas de } \\
\text { la cuenca del } \\
\text { río Cacarica } \\
\text { (operación } \\
\text { génesis) vs } \\
\text { Colombia }\end{array}$ & $\begin{array}{l}\text { - Otorgar indemnización por daños morales y materiales. } \\
\text { - } \text { Prindar atención médica y sicológica. } \\
\text { - Realizar un acto público de reconocimiento de su responsabilidad. } \\
\text { - Investigar y sancionar a los responsables de los hechos. } \\
\text { - Restituir el efectivo uso, goce y posesión de los territorios } \\
\text { reconocidos por el Consejo Comunitario de las Comunidades de } \\
\text { la Cuenca del río Cacarica. } \\
\text { - Garantizar que las condiciones de los territorios que se } \\
\text { restituyan sean adecuadas para la seguridad y vida digna de } \\
\text { la comunidad. }\end{array}$ \\
\hline $\begin{array}{c}2013 \\
\text { García Cruz } \\
\text { y Sánchez } \\
\text { Silvestre vs } \\
\text { Estados Unidos } \\
\text { Mexicanos }\end{array}$ & $\begin{array}{l}\text { - Investigar y sancionar a los responsables de los hechos. } \\
\text { - } \text { Eliminar antecedentes penales. } \\
\text { - } \text { Conceder becas a las víctimas. } \\
\text { - Otorgar indemnización por daños morales y materiales. } \\
\text { - Realizar un acto público de reconocimiento de su responsabilidad. } \\
\text { - Garantizar la educación de las víctimas. } \\
\text { - Entregar en propiedad una vivienda. } \\
\text { - Publicar la sentencia en el diario oficial. } \\
\text { - Capacitar a operadores de justicia sobre la procuración e } \\
\text { impartición de justicia bajo los estándares internacionales } \\
\text { más altos para que puedan identificar, reaccionar, prevenir, } \\
\text { denunciar y sancionar el uso de técnicas de tortura. }\end{array}$ \\
\hline
\end{tabular}


Cont...

\begin{tabular}{|c|c|}
\hline Caso & Reparación \\
\hline $\begin{array}{l}2014 \\
\text { Liakat Ali } \\
\text { Alibux vs } \\
\text { Suriname }\end{array}$ & $\begin{array}{l}\text { - Otorgar indemnización por daños morales y materiales. } \\
\text { - Publicar la sentencia en el diario oficial. }\end{array}$ \\
\hline $\begin{array}{l}2015 \\
\text { Caso Espinoza } \\
\text { Gonzáles vs } \\
\text { Perú }\end{array}$ & $\begin{array}{l}\text { Investigar y sancionar a los responsables de los hechos. } \\
\text { - Brindar atención médica y psicológica. } \\
\text { - Publicar la sentencia en el diario oficial. } \\
\text { - Otorgar indemnización por daños morales y materiales. } \\
\text { torturra, violación sexual y otras formas de violencia sexual. } \\
\text { - Implementar programas de educación y capacitación dirigidos } \\
\text { a quienes están encargados de la persecución penal y su } \\
\text { judicialización con base en los estándares en los estándares } \\
\text { establecidos en la sentencia. }\end{array}$ \\
\hline $\begin{array}{l}2015 \\
\text { Caso Cruz } \\
\text { Sánchez y otros } \\
\text { vs Perú }\end{array}$ & $\begin{array}{l}\text { - Brindar atención médica y sicológica. } \\
\text { - Realizar un acto público de reconocimiento de su } \\
\text { responsabilidad. } \\
\text { - Investigar y sancionar a los responsables de los hechos. }\end{array}$ \\
\hline
\end{tabular}

Fuente: Elaboración propia.

Observamos que la Corte sigue conociendo sobre casos relacionados con masacres, desapariciones y violencia basada en género, pero también empieza a conocer otro tipo de situaciones de violaciones de derechos humanos, como la prohibición de fecundación in vitro, lo que lleva a adoptar otros tipos de medidas, tales como incluir en el programa de salud de Costa Rica los tratamientos de este tipo de fecundación, lo cual si bien hace referencia a derechos civiles y políticos, está íntimamente conectado con derechos sociales, económicos y culturales, lo que constituye un avance importante en la materia.

Igualmente, la Corte Interamericana consolida el denominado Control de convencionalidad, el cual se adoptó por primera vez en el caso Almonacid Arellano ${ }^{10}$ con varios objetivos: el primero, es lograr que no existan incompatibilidades entre las normas internas de los Estados y la Convención Americana, junto con los otros instrumentos que hacen parte

${ }^{10}$ OEA. CorteIDH. Caso Almonacid Arellano y otros vs Chile, 2006. 
del Sistema Interamericano de Derechos Humanos; segundo, brindar una protección real y efectiva a los derechos humanos reconocidos en los mencionados tratados, y tercero, reafirmar la prevalencia del derecho internacional sobre el derecho interno.

La CorteIDH a través de su jurisprudencia fue creando la base y estableciendo el criterio de reparación integral, pero de nada serviría este concepto si se encuentra en contradicción con la legislación interna y la Convención. El artículo 2 de la Convención Americana establece las obligaciones de garantías y respeto consagradas en el artículo 1.1, con el deber de adoptar disposiciones de derecho interno para garantizar los derechos de la $\mathrm{CADH}^{11}$. Cuando se acreditan situaciones incompatibles con la Convención Americana que derivan en una violación, la CorteIDH ordena la "modificación, la derogación, o de algún modo anulación, o la reforma de las normas o prácticas que tengan esos alcances, según corresponda ${ }^{12}$."

\section{Las medidas de reparación adoptadas por el Consejo de Estado $^{13}$}

Desde el 2007, el cambio jurisprudencial del Consejo de Estado en materia de reparación judicial a las víctimas de violaciones graves de DDHH ha avanzado notablemente toda vez que empezó a adoptar los criterios de reparación integral en el marco del Derecho Internacional de los Derechos Humanos, lo cual constituye un avance positivo en la materia. Sin embargo, con el fin de analizar la compatibilidad de las medidas adoptadas por el Consejo de Estado con los estándares internacionales, se relacionan a continuación algunos casos de proferidos por dicho tribunal:

\footnotetext{
${ }^{11}$ OEA. CorteIDH. Caso de la Masacre de las Dos Erres vs Guatemala, 2009.

12 OEA. CorteIDH. Caso La Cantuta vs Perú. 2006, párr. 172.

${ }^{13}$ El Consejo de Estado es una alta corte colombiana, que es la máxima jurisdicción de lo contencioso administrativo y órgano consultivo del Gobierno.
} 


\section{Tabla 5}

\section{Casos Consejo de Estado sobre Reparación Integral.}

\begin{tabular}{|c|c|c|}
\hline Caso & Hechos sustanciales & Reparación \\
\hline 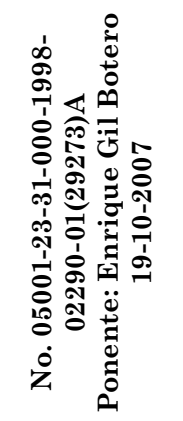 & $\begin{array}{l}\text { El } 22 \text { de octubre de } 1997 \text {, a eso de las } \\
\text { 6:30 de la noche, aproximadamente, se } \\
\text { hicieron presentes soldados del Ejército } \\
\text { Nacional en la finca de los señores Fabio } \\
\text { Zuleta y Omar Ortiz. Los increparon, } \\
\text { según adujeron, por ser colaboradores } \\
\text { de la guerrilla; luego de conversar con } \\
\text { ellos durante un lapso aproximado de } 10 \\
\text { minutos, procedieron a darles muerte y, } \\
\text { adicionalmente, amenazaron a los traba- } \\
\text { jadores para que guardaran silencio so- } \\
\text { bre lo acontecido. }\end{array}$ & $\begin{array}{l}\text { Aquí se repara solamente por concep- } \\
\text { to de perjuicios morales, es decir, se } \\
\text { repara monetariamente únicamente. }\end{array}$ \\
\hline 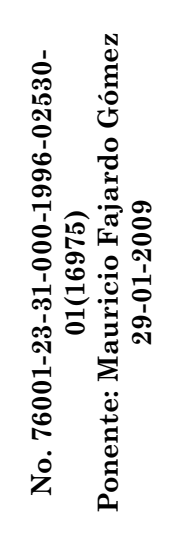 & $\begin{array}{l}\text { El } 29 \text { de abril de } 1994 \text {, (5) cinco personas } \\
\text { entre ellas (2) mujeres, fueron encontra- } \\
\text { das muertas a orillas del río Meléndez, } \\
\text { en el sitio conocido como Las Brujas, a un } \\
\text { lado de la vía que conduce a la loma de Alto } \\
\text { Nápoles. Dentro de las personas muertas } \\
\text { ese día se encontraba Elizabeth Hoyos, de } \\
26 \text { años y madre de (4) cuatro hijos, quien } \\
\text { para esa época trabajaba como ayudante } \\
\text { de construcción y se desempenaba como } \\
\text { vendedora de publicidad. La autoría del } \\
\text { crimen se adjudicó a un escuadrón de la } \\
\text { muerte que pretendía hacer una aparente } \\
\text { limpieza social, escuadrón que más tarde } \\
\text { se supo estaba integrado por agentes de la } \\
\text { Policía Metropolitana de Cali. }\end{array}$ & $\begin{array}{l}\text { La reparación se hace por concepto } \\
\text { de perjuicios morales y se repara } \\
\text { a los hijos, cónyuge de la víctima y } \\
\text { hermanos. }\end{array}$ \\
\hline 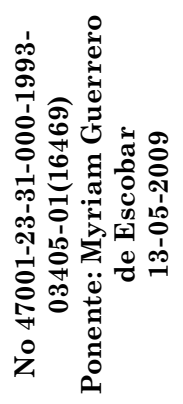 & $\begin{array}{l}\text { Los actores señalaron que las víctimas, } \\
\text { quienes se dedicaban al trasporte de } \\
\text { frutas, fueron retenidas ilegalmente por } \\
\text { miembros pertenecientes a la policía del } \\
\text { municipio de Guamal, departamento del } \\
\text { Magdalena con el propósito de despojar- } \\
\text { los del dinero que llevaban consigo. Los } \\
\text { obligaron a abordar el vehículo oficial en } \\
\text { el que se movilizaban y sus cuerpos sin } \\
\text { vida fueron encontrados minutos después } \\
\text { en un paraje del corregimiento de Muri- } \\
\text { llo con señales de tortura. }\end{array}$ & $\begin{array}{l}\text { Se repara por concepto de perjuicios } \\
\text { morales, perjuicios materiales en } \\
\text { modalidad de lucro cesante. }\end{array}$ \\
\hline
\end{tabular}




\begin{tabular}{|c|c|c|}
\hline Caso & Hechos sustanciales & Reparación \\
\hline 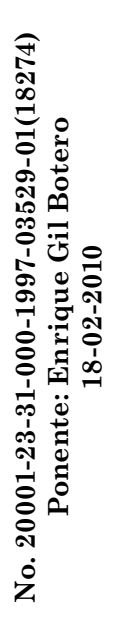 & $\begin{array}{l}\text { En el año 1995, fueron asesinadas cin- } \\
\text { cuenta y cuatro (54) personas en el mu- } \\
\text { nicipio de San Alberto, entre ellas, el se- } \\
\text { ñor personero municipal, Jorge Enrique } \\
\text { León Chávez. } \\
\text { El } 27 \text { de noviembre de 1997, la señora } \\
\text { cónyuge del señor difunto personero del } \\
\text { municipio de San Alberto, Cesar, Blan- } \\
\text { ca Rosalba Prieto Rubio, quien obra en } \\
\text { nombre propio y en representación de } \\
\text { sus hijos menores, interpusieron de- } \\
\text { manda de reparación directa para que } \\
\text { se declare patrimonialmente a la Na- } \\
\text { ción-Ministerio de Defensa-Policía Na- } \\
\text { cional, por los perjuicios a ellos ocasio- } \\
\text { nados con motivo de la muerte de Jorge } \\
\text { Enrique León Chávez, ocurrida el } 24 \text { de } \\
\text { noviembre de } 1995 \text {. }\end{array}$ & $\begin{array}{l}\text { Se repara por concepto de lucro ce- } \\
\text { sante y por concepto de perjuicios } \\
\text { morales. }\end{array}$ \\
\hline 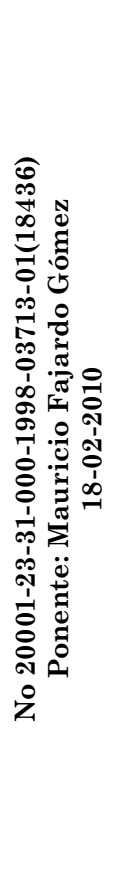 & $\begin{array}{l}\text { En la noche del } 14 \text { de febrero de } 1996, \\
\text { un grupo paramilitar cometió múltiples } \\
\text { atropellos contra las familias campesi- } \\
\text { nas ubicadas en la hacienda "Bellacruz" } \\
\text { en la vereda "Vistahermosa" del depar- } \\
\text { tamento del Cesar. Debido a lo anterior, } \\
\text { las familias campesinas suscribieron } \\
\text { acuerdos con el INCORA, y se creó una } \\
\text { comisión de verificación de tales acuer- } \\
\text { dos. No obstante, las condiciones de } \\
\text { seguridad de los campesinos siguieron } \\
\text { siendo precarias. En virtud de tales } \\
\text { acuerdos varios campesinos decidieron } \\
\text { volver a sus predios, entre ellos los her- } \\
\text { manos Eder, Eliseo y Manuel Narváez, } \\
\text { siendo asesinados los dos primeros el } \\
\text { día } 28 \text { de septiembre de } 1996 \text { por el } \\
\text { mismo grupo paramilitar que los había } \\
\text { expulsado. Finalmente, manifestaron } \\
\text { que, debido a las múltiples amenazas } \\
\text { y a la falta de garantías de seguridad, } \\
\text { el señor Manuel Narváez Corrales y los } \\
\text { integrantes de su familia se vieron obli- } \\
\text { gados a abandonar el país en enero de } \\
\text { 1997. }\end{array}$ & $\begin{array}{l}\text { - Por daño a la alteración grave de } \\
\text { las condiciones de existencia. } \\
\text { Por daño moral, a favor de las } \\
\text { personas afectadas. } \\
\text { Medidas de naturaleza no pecu- } \\
\text { niaria: oficiar a la Fiscalía Gene- } \\
\text { ral de la Nación para que inicie } \\
\text { las respectivas investigaciones } \\
\text { dirigidas a esclarecer la respon- } \\
\text { sabilidad penal y los presuntos } \\
\text { responsables de los hechos. } \\
\text { - Se fijó una placa, en el Comando } \\
\text { de Policía, con el propósito de que } \\
\text { las nuevas generaciones conocie- } \\
\text { ran acerca de los hechos que die- } \\
\text { ron lugar al presente caso. }\end{array}$ \\
\hline
\end{tabular}


Cont...

\begin{tabular}{|c|c|c|}
\hline Caso & Hechos sustanciales & Reparación \\
\hline 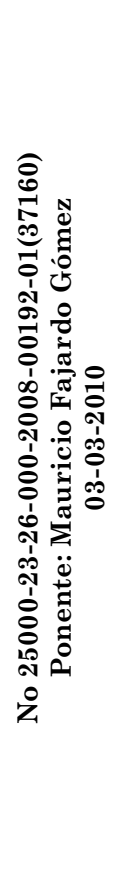 & $\begin{array}{l}\text { El } 10 \text { de diciembre de 1982, funcionarios } \\
\text { del DAS retuvieron a la señora Patricia } \\
\text { Rivera Chávez y a sus dos hijas menores } \\
\text { de edad, Gilma Ileana y Catherine Ber- } \\
\text { nal Rivera, en el barrio Calvo Sur de la } \\
\text { ciudad de Bogotá D.C. Al percatarse de } \\
\text { tal situación, el señor Marco Antonio } \\
\text { Crespo procedió a auxiliar a sus vecinas, } \\
\text { pero fue retenido junto con ellas, sin que } \\
\text { se volviera a tener noticia de las personas } \\
\text { en comento. } \\
\text { A partir de ese momento, la señora Ana } \\
\text { Alicia Rodríguez Prieto y sus hijos, em- } \\
\text { prendieron la búsqueda de su ser queri- } \\
\text { do, sin que en la actualidad (año 2010) } \\
\text { se haya logrado establecer plenamente la } \\
\text { suerte que aquél corrió. } \\
\text { La señora Ana Alicia Rodríguez Prie- } \\
\text { to, a través de la Procuraduría } 7^{a} \text { en lo } \\
\text { Judicial, citó al DAS con el fin de lograr } \\
\text { un acuerdo conciliatorio sin que arribara } \\
\text { a convenio alguno y, por lo tanto, no se } \\
\text { ha llevado a cabo la reparación integral } \\
\text { de los perjuicios derivados de la desapa- } \\
\text { rición forzada del señor Marco Antonio } \\
\text { Crespo. }\end{array}$ & $\begin{array}{l}\text { Por concepto de perjuicios de daño } \\
\text { moral. } \\
\text { - Por concepto de perjuicios inma- } \\
\text { teriales en la modalidad de alte- } \\
\text { ración grave de las condiciones de } \\
\text { existencia. } \\
\text { - Por concepto de perjuicios mate- } \\
\text { riales en la modalidad de lucro } \\
\text { cesante. }\end{array}$ \\
\hline
\end{tabular}

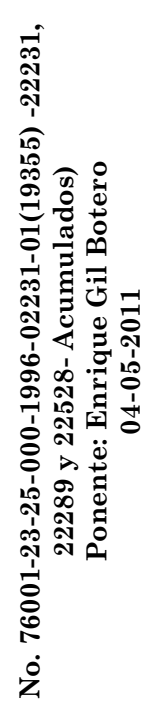

El 27 de abril de 1994, Francisco Ortiz Jiménez, Juan Carlos Muriel Guerrero y María del Carmen Leguizamón se encontraban reunidos con un grupo de amigos en la casa de Tarcicio Córdoba Mosquera, localizada en la ciudad de Cali, cuando a las 11:30 de la noche irrumpieron en la residencia un número aproximado de 10 personas encapuchadas y armadas, quienes manifestaron que eran de la "judicial" y les ordenaron a todos subir a una camioneta Trooper blanca para ser "supuestamente" conducidos a una estación de policía. El automotor se dirigió a la orilla del río Meléndez, sector El Polvorín, lugar donde los hicieron descender y acostarse sobre el pasto bajo el anuncio de que los iban a matar. Los asesinos empezaron a consumar el acto criminal para lo cual dispararon sus armas contra los indefensos ciudadanos, de los cuales sólo dos de ellos alcanzaron a escapar.

- Por concepto de perjuicios morales.

- Por concepto de daños materiales en la modalidad de lucro cesante.

- Se oficiará a la Fiscalía General de la Nación para que inicie las respectivas investigaciones dirigidas a esclarecer la responsabilidad penal.

- Los familiares de las víctimas deberán ser citados al proceso con el fin de que tengan pleno conocimiento sobre la verdad de los hechos.

- La sentencia fue publicada en un lugar visible. 


\begin{tabular}{|c|c|c|}
\hline Caso & Hechos sustanciales & Reparación \\
\hline 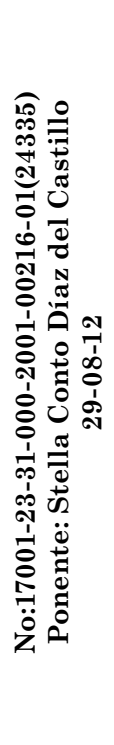 & $\begin{array}{l}\text { El } 4 \text { de marzo de 1999, el señor Agustín } \\
\text { Rojas, de } 80 \text { años de edad, indígena de } \\
\text { la comunidad El Rodeo, perteneciente } \\
\text { al resguardo Cañamomo y Lomaprieta } \\
\text { asentado en jurisdicción de los munici- } \\
\text { pios de Riosucio y Supía, Caldas, resultó } \\
\text { herido en el abdomen como consecuencia } \\
\text { del disparo propinado por uniformados } \\
\text { adscritos al Batallón Ayacucho de la ciu- } \\
\text { dad de Manizales, por lo que fue trasla- } \\
\text { dado al Hospital de Riosucio por miem- } \\
\text { bros del batallón aludido en compañía de } \\
\text { su yerno Bernardo Becerra, a quien el } \\
\text { Ejército Nacional le dijo que "debía afir- } \\
\text { mar que el ataque había sido por parte de } \\
\text { la guerrilla". } \\
\text { El señor Agustín Rojas falleció el día } 8 \\
\text { del mismo mes en el Hospital de Caldas } \\
\text { por insuficiencia respiratoria aguda, se- } \\
\text { cundaria a herida en el abdomen causada } \\
\text { con proyectil de arma de fuego de alta } \\
\text { velocidad. }\end{array}$ & $\begin{array}{l}\text { - Se declara patrimonialmente res- } \\
\text { ponsable a la Nación-Ministerio de } \\
\text { Defensa-Ejército Nacional por los } \\
\text { perjuicios morales que sufrieron } \\
\text { las víctimas. } \\
\text { - Por el concepto de perjuicios mo- } \\
\text { rales. } \\
\text { - Por concepto de perjuicios mate- } \\
\text { riales. } \\
\text { - Iniciar investigaciones para deter- } \\
\text { minar las correspondientes res- } \\
\text { ponsabilidades. } \\
\text { - Brindar gratuitamente, a través } \\
\text { de sus instituciones de salud espe- } \\
\text { cializadas, el tratamiento médico y } \\
\text { psicológico. } \\
\text { - Publicar en el diario oficial la noti- } \\
\text { ficación de la sentencia. } \\
\text { Realizar un acto público de reco- } \\
\text { nocimiento de su responsabilidad. }\end{array}$ \\
\hline 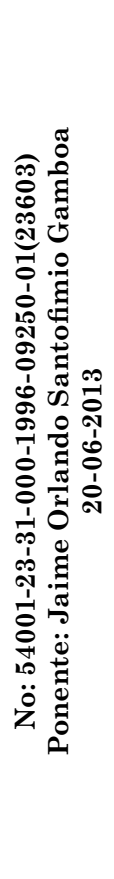 & $\begin{array}{l}\text { El día } 2 \text { de noviembre de } 1993 \text { fueron } \\
\text { detenidos Ramón Alirio Pérez Vargas, } \\
\text { Gerardo Liévano y (sic) Nelson Ortega } \\
\text { en el restaurante La Fondita Paisa, jun- } \\
\text { to al hotel Chucarima-Cúcuta (sic), lugar } \\
\text { en el que fueron golpeados y sacados por } \\
\text { miembros de la Unidad Contraguerrilla } \\
\text { de la División de Especiales del Batallón } \\
\text { Maza Mecanizado. De allí los condujeron } \\
\text { al sitio denominado Bocatoma, donde } \\
\text { los torturaron produciéndoles múltiples } \\
\text { heridas y secuelas físicas, de las cuales } \\
\text { aún quedan rastros, como la pérdida de } \\
\text { su dentadura, amígdalas y subsecuentes } \\
\text { operaciones de una hernia inguinal. }\end{array}$ & $\begin{array}{l}\text { - Por concepto de perjuicios morales. } \\
\text { Poner en conocimiento las viola- } \\
\text { ciones al derecho internacional } \\
\text { de los derechos humanos al Comi- } \\
\text { té contra la Tortura de Naciones } \\
\text { Unidas. } \\
\text { - La sentencia en su parte resoluti- } \\
\text { va deberá ser puesta a disposición } \\
\text { de los miembros de las entidades } \\
\text { demandadas por todos los canales } \\
\text { de información. } \\
\text { - Ordena la compulsa de copias a la } \\
\text { Fiscalía General de la Nación para } \\
\text { que se investigue penalmente a los } \\
\text { responsables de los hechos. } \\
\text { - Ordena al Estado aplicar todas } \\
\text { las medidas que comprendan la } \\
\text { garantía de no repetición de los } \\
\text { hechos violatorios de los derechos } \\
\text { humanos. } \\
\text { Ordena que por Secretaría de la } \\
\text { Sección se remita la sentencia al } \\
\text { Centro de Memoria Histórica para } \\
\text { que repose dentro de los archivos } \\
\text { que dicha entidad tenga respecto } \\
\text { al conflicto armado interno. }\end{array}$ \\
\hline
\end{tabular}


Cont...

\begin{tabular}{|c|c|c|}
\hline Caso & Hechos sustanciales & Reparación \\
\hline 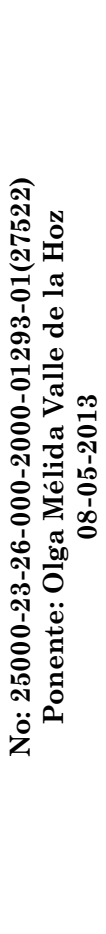 & $\begin{array}{l}\text { El día } 16 \text { de abril de } 1998 \text { se recibe de } \\
\text { la firma Patólogos Asociados el resul- } \\
\text { tado de una citología mamaria derecha } \\
\text { (punción nódulo mamario) con diagnós- } \\
\text { tico histopatológico que expresa: "Bacaf } \\
\text { mama derecha. Ver descripción micros- } \\
\text { cópica" de la señora Rósula Jaramillo } \\
\text { Benavides. El Hospital Militar emite el } \\
\text { siguiente informe el día } 4 \text { de noviembre: } \\
\text { "Los cortes muestran glándula mamaria } \\
\text { con una lesión proliferativa atípica, que } \\
\text { por la característica del corte (grueso) } \\
\text { no permite con claridad establecer diag- } \\
\text { nóstico de carcinoma. Se debe remitir el } \\
\text { bloque de parafina." Posteriormente, sin } \\
\text { atender la solicitud del servicio de pato- } \\
\text { logía y sin esperar los resultados de la } \\
\text { revisión que el mismo hospital había or- } \\
\text { denado, el día } 21 \text { de noviembre de } 1998 \\
\text { se le realiza la mastectomía radical mo- } \\
\text { dificada (ablación del seno derecho). De } \\
\text { acuerdo con los informes, el tumor no era } \\
\text { maligno, ni había presencia de un carci- } \\
\text { noma y, que, por lo tanto, la cirugía por } \\
\text { la cual se le extirpó el seno fue innece- } \\
\text { saria, lo cual constituye una falla en el } \\
\text { servicio que le ha causado perjuicios a los } \\
\text { demandantes. }\end{array}$ & $\begin{array}{l}\text { - Condenar a la entidad a pagar } \\
\text { 100 SMMLV para cada uno de los } \\
\text { afectados por concepto de perjuicio } \\
\text { fisiológico (daño a la salud) } \\
\text { - Condenar al Hospital Militar Cen- } \\
\text { tral a que se ordene la práctica de } \\
\text { exámenes, análisis y las cirugías } \\
\text { necesarias para la reconstrucción } \\
\text { física del seno, así como los trata- } \\
\text { mientos de rehabilitación física y } \\
\text { sicológica requeridos por la lesio- } \\
\text { nada. }\end{array}$ \\
\hline
\end{tabular}

El día 12 de octubre de 2003, siendo aproximadamente las 6:15 a.m., la señora Miralba Ríos Otalvaro se encontraba departiendo con unos amigos en la trasversal 29a No. 19-10, Barrio Sábanas del Valle, de la ciudad de Valledupar, cuando intempestivamente se presentaron agentes de la Policía Nacional, vestidos de civil, quienes sin orden judicial ni queja alguna de la comunidad, manifestaron que iban a detenerla, y la agredieron verbal y físicamente. Ante esta situación, la señora Miralba Ríos, quien portaba un arma de fuego de su propiedad debidamente amparada, se defendió; sin embargo, posteriormente a ser neutralizada y capturada, recibió múltiples golpes por parte de dichos agentes estatales, que le produjeron graves fracturas en el rostro y en el cuerpo.
- Otorgar indemnización por perjuicios.

- Enviar una copia de la sentencia a la Alta Consejera Presidencial para la Equidad de la Mujer (ACPEM), la Sala Administrativa del Consejo Superior de la JudicaturaComisión Nacional de Género de la Rama Judicial y la Procuraduría General de la Nación para la creación de políticas públicas de igualdad de género y vigilar el cumplimiento de las obligaciones asumidas por la Policía Nacional en materia de no violencia de género. 


\begin{tabular}{lll}
\hline Caso & Hechos sustanciales & Reparación \\
\hline
\end{tabular}

El 4 de septiembre de 1999, a las 9:00 p.m., aproximadamente, la joven XXX XXX XXX, en compañía de sus amigos XXX $\mathrm{xxx}$ y $\mathrm{xxx} \mathrm{xxx}$, se dirigía a su casa luego de terminada una reunión organizada por la parroquia municipal de Tame, Arauca, cuando, a la altura de la plazoleta "Lanceros", fueron abordados por dos personas que se movilizaban en una motocicleta y que, luego de amenazar a los jóvenes con un arma de fuego, la obligaron a subir al vehículo en el cual partieron por la vía que conduce a Bogotá. Al llegar al sitio conocido como "Villa Olímpica", el conductor perdió el control del vehículo y sus ocupantes cayeron al suelo. Acto seguido, los dos sujetos arrastraron a la joven a un lado de la carretera, la despojaron de sus ropas, la sometieron por la fuerza y la violentaron sexualmente. Al partir, le advirtieron que la matarían a ella y su familia si llegaba a revelar lo ocurrido. Pasados unos minutos, la víctima salió a la vía con rumbo a su casa y en el camino fue auxiliada por el señor xxx xxx que pasaba por el lugar. El hermano de la víctima xxx xxx la encontró y se dirigió con ella a la estación de policía de la localidad para denunciar los hechos. En el camino, a la altura del establecimiento "La Mejor Esquina", observaron a los agresores, quienes intentaron detenerlos, pero aquellos hicieron caso omiso y continuaron la marcha. Ya en la estación de policía, a la que también llegaron los atacantes, los funcionarios de turno se negaron a recibir la denuncia.
- Pagar por concepto de perjuicios morales.

- Pagar por concepto de reparación del daño a la salud.

- Ordenar al Ministerio de DefensaEjército Nacional la prestación del servicio médico, psicológico y psiquiátrico.

- Ordenar al Ministerio de DefensaEjército Nacional diseñar e implementar un programa de capacitación de los miembros del Ejército, orientado a la amplia difusión y socialización de los derechos de la mujer.

- Publicar la misma en el portal web del Ministerio de Defensa, que deberá disponer un enlace visible en su página inicial, de fácil acceso, con un título respetuoso de las víctimas y con reserva de identidad de las mismas.

- Remitir copia de la sentencia a la Policía Nacional, Fiscalía General de la Nación, Alta Consejería para la Equidad de la Mujer, sala Administrativa del Consejo Superior de la Judicatura, Comisión Nacional de Género de la Rama Judicial, Procuraduría General de la Nación, para sus fines pertinentes.

El día 28 de julio de 1998, aproximadamente a las doce de la noche, el señor Bolívar Ezequiel Chamorro Narváez se desplazaba desde el polideportivo del barrio La Independencia del municipio de Mocoa hacia su casa de habitación, momento en el cual fue interceptado por dos motocicletas en las que se desplazaban agentes de la SIJIN y dos particulares llamados Hernando Guerrero y Pablo Toro. Afirma la demanda que los uniformados descendieron de la moto y con sus armas de dotación oficial asesinaron al señor Bolívar Ezequiel Chamorro y, posteriormente, huyeron del lugar de los hechos.

- A título de perjuicios materiales, en la modalidad de lucro cesante.

- Acto solemne de presentación de excusas públicas a los familiares de la víctima. 
Una vez analizados los casos, es preciso establecer que Colombia por ser parte de la Convención Americana tiene la obligación internacional de adoptar en su derecho interno los estándares internacionales de reparación integral; adicional a esto, en virtud del artículo 93 de la Constitución Política, que reconoce el Bloque de Constitucionalidad, en el que los tratados internacionales que reconocen derechos humanos ratificados por el Estado colombiano tienen jerarquía constitucional, la $\mathrm{CADH}^{14}$ tiene rango constitucional y todas las normas de inferior jerarquía deben estar en armonía con la Constitución Política y la Convención Americana, de lo contrario se produce la responsabilidad internacional del Estado.

Así mismo, la Corte Constitucional determinó que "la jurisprudencia de las instancias internacionales, encargadas de interpretar esos tratados, constituye un criterio hermenéutico relevante para establecer el sentido de las normas constitucionales sobre derechos fundamentales"15. En ese sentido, los tribunales nacionales tienen el deber de adoptar las disposiciones internacionales en materia de derechos humanos.

Puntualmente, en materia de reparación, se puede determinar que el Consejo de Estado ha hecho un trabajo significativo. Desde el 2007 empezó a adoptar estos criterios y a lo largo de su jurisprudencia ha ordenado medidas de satisfacción y garantías de no repetición, tales como, la publicación de la sentencia, ofrecimiento de disculpas públicas, atención médica y sicológica, y orden a la Fiscalía General de la Nación que investigue a los responsables de los hechos. Todo esto es muy positivo por ser un tribunal de avanzada que promueve la protección de los derechos humanos.

No se puede afirmar que en todos los casos relacionados con graves violaciones de derechos humanos ha ordenado la reparación integral. En cuanto a las medidas de rehabilitación, se entiende como la recuperación concreta y particular en materia legal, laboral, física y psicológica de las víctimas, pero como se observa en las tablas anteriores, el Consejo de Estado no dispone a favor de las víctimas órdenes de rehabilitación afectados por los

\footnotetext{
${ }^{14}$ Ley 16 de 1972, Por medio de la cual se aprueba la Convención Americana sobre Derechos Humanos "Pacto de San José de Costa Rica", firmado en San José, Costa Rica, el 22 de noviembre de 1969.

${ }^{15}$ Corte Constitucional. Sentencia C-010-00.
} 
hechos violatorios, a pesar de la acreditación del sufrimiento y la afectación psicológica padecida. Estas órdenes más integrales se han proferido en los últimos años.

En relación con la indemnización, es preciso resaltar que el Consejo de Estado no se acerca a los estándares interamericanos porque limita los montos indemnizatorios por perjuicios morales hasta 100 S.M.L.V, monto equiparado al daño antijurídico que no se relaciona con violaciones graves a DDHH, por lo tanto, el Consejo de Estado parece que ha venido homogenizando, es decir, los está reparando a todos de la misma manera sin siquiera tomar en consideración las diferentes situaciones provenientes del daño antijurídico que no guarda relación con violaciones a DDHH.

En la mayoría de casos de desaparición forzada y homicidio, el Consejo de Estado no reconoció a las víctimas directas perjuicios morales consecuencia de la violación, además de que a las víctimas indirectas no les correspondió ningún valor por la violación, por lo tanto, causó un empobrecimiento al no garantizar el pago de una justa indemnización a los familiares de las víctimas ni reparar de alguna manera las consecuencias negativas que se generaron por causa de la violación.

Según Carlos López Cárdenas:

La Corte IDH, en varias ocasiones al liquidar los perjuicios morales de las víctimas directas e indirectas opta por aumentar el valor asignado a estas como compensaciones, ha presentado una especial atención al mayor padecimiento sufrido ${ }^{16}$ por las víctimas directas en los casos de violaciones al derecho a la vida e integridad personal; así como por las mujeres víctimas de abuso sexual, o por aquellas que al momento de la ocurrencia de los hechos se encontraban en estado de embarazo, ${ }^{17}$ o por el daño moral de los niños muertos o sobrevivientes, cuando estos son víctimas directas de la violación por considerar que se trata de una población especial cuyo dolor se acentúa por la violación convencional (López, 2009).

\footnotetext{
${ }^{16}$ OEA. CorteIDH. Caso Aloebotoe, 1991; se indicó que debía otorgarse una suma de dinero igual para todas las víctimas con excepción de Richenel Voola, a quien la Corte le asigno una reparación que superaba un tercio a la de los otros.

${ }^{17}$ OEA. CorteIDH. Caso Miguel Castro Castro, 2006; la Corte advierte que las internas al momento de los hechos se encontraban con 7, 8 y 5 meses de embarazo y que el Estado desatendió las necesidades básicas de salud frente a dos de ellas, así como las referentes a la atención después del parto de la señora Quispe, por lo que fijo una indemnización adicional.
} 
Otro ejemplo, y que se puede observar plenamente en las reparaciones por parte del CE, es que no ha ordenado en sus sentencias medidas de capacitación en DDHH al personal judicial y militar, para generar conciencia tanto en la población general como a los funcionarios públicos.

\section{CONCLUSIONES}

La Corte Interamericana ha desarrollado un precedente jurisprudencial interamericano en materia de reparación integral en el que incluye la restitución, medidas de satisfacción, rehabilitación, de no repetición e indemnización. Este precedente ha servido para que otros Estados adopten esos criterios en el derecho interno y así satisfacer los derechos de las víctimas y al mismo tiempo cumplir con sus obligaciones internacionales. Esto significa que esos casos emblemáticos que el tribunal ha conocido han sido de tanta efectividad que llevó a otros Estados, con el fin de evitar condenas futuras, a adoptar internamente las medidas tendientes a prevenir la comisión de hechos similares, lo que refleja un aspecto muy positivo de la receptividad del SIDH por parte de los Estados.

El Estado colombiano, a través del Consejo de Estado, desde el 2007 (pero es a partir del 2011 que adopta la mayoría de los criterios de reparación integral), ha incorporado en su derecho interno los estándares de reparación integral adoptados por la Corte Interamericana, tales como: medidas de satisfacción, garantías de no repetición y medidas de rehabilitación, lo cual constituye un gran avance en la garantía de los derechos humanos. Esto significa que ha evolucionado la atención prestada por parte de los Estados hacia las víctimas que han sufrido violaciones graves a sus DDHH.

El Consejo de Estado falla en el monto que ordena medidas por concepto de indemnización, que es muy inferior a las ordenadas en el marco del derecho internacional. Igualmente, falla en el reconocimiento integral de las reparaciones tanto a las víctimas directas como indirectas, pues en determinados casos, como los de desaparición forzada, no ha reconocido los daños morales padecidos por estos hechos. 
Pese a las observaciones planteadas se observa que el Estado colombiano, a través del Consejo de Estado, ha venido paulatinamente cumpliendo sus obligaciones internacionales de reparar integralmente a las víctimas en el marco de un proceso judicial, dado que los procedimientos de reparación administrativa no son objeto de estudio. Este precedente jurisprudencial interamericano y nacional constituye para las víctimas y sus defensores una herramienta de litigio muy valiosa para la exigibilidad de sus derechos, toda vez que es obligatoria, con excepciones, la adopción de los precedentes por parte de los jueces, lo que en teoría facilitaría el desarrollo del proceso judicial.

Si bien se observa un gran avance en el cumplimiento de las obligaciones internacionales en materia de reparación por parte del Consejo de Estado, falta avanzar en la adopción plena, en todos los casos, de los estándares internacionales de reparación a favor de las víctimas, dado que si esto no se hace, serán muchas las víctimas que seguirán acudiendo a las instancias internacionales de protección de derechos humanos con el fin de lograr justicia en sus casos, lo que conllevará a la declaratoria de la responsabilidad internacional del Estado colombiano.

\section{REFERENCIAS}

García, S. (2003). Reparaciones del Sistema Interamericano de Protección de Derechos Humanos. En, Corte Interamericana de Derechos Humanos, El Sistema Interamericano de Protección de los Derechos Humanos el umbral del siglo XXI. [Memoria seminario]. $2^{\text {a. }}$ Ed. San José, Costa Rica.

López, C. M. (2009). Aproximación a un estándar de reparación integral procesos colectivos de violación a los derechos humanos. Jurisprudencia de la Corte Interamericana de Derechos Humanos. Revista Estudios Socio-Jurídicos, 11(2), 301-334.

OEA. Corte Interamericana de Derechos Humanos. (29 de julio de 1988). Sentencia del Caso Velásquez Rodríguez vs Honduras.

OEA. CorteIDH. (4 de Diciembre de 1991). Sentencia del Caso Aloebotoe vs Suriname.

OEA. CorteIDH. (10 de Septiembre de 1995). Sentencia del Caso Neira Alegría y otros vs Perú.

OEA. CorteIDH. (8 de Diciembre de 1995). Sentencia del Caso Caballero Delgado y Santana vs Colombia. 
OEA. CorteIDH. (2 de Febrero de 1996). Sentencia del Caso Garrido y Baigorria vs Argentina.

OEA. CorteIDH. (17 de Septiembre de 1997). Sentencia del Caso Loayza Tamayo vs Perú.

OEA. CorteIDH. (11 de Noviembre de 1999). Sentencia del Caso del Caracazo vs Venezuela.

OEA. CorteIDH. (19 de Noviembre de 1999). Sentencia del Caso de los "Niños de la Calle" (Villagrán Morales y otros) vs Guatemala.

OEA. CorteIDH. (16 de Agosto de 2000). Sentencia del Caso Durand y Ugarte vs Perú.

OEA. CorteIDH. (26 de Enero de 2000). Sentencia del Caso Trujillo Oroza vs Bolivia.

OEA. CorteIDH. (25 de Noviembre de 2000). Sentencia de fondo del Caso Bámaca Velásquez vs Guatemala.

OEA. CorteIDH. (18 de Agosto de 2000). Sentencia del Caso Cantoral Benavides vs Perú.

OEA. CorteIDH. (14 de Marzo de 2001). Sentencia del Caso Barrios Altos vs Perú.

OEA. CorteIDH. (31 de Agosto de 2001). Sentencia del Caso de la comunidad Mayagna (Sumo) Awas Tingni vs Nicaragua.

OEA. CorteIDH. (21 de Junio de 2002). Sentencia del Caso Hilaire, Constantine y Benjamin y otros vs Trinidad y Tobago.

OEA. CorteIDH. (18 de Septiembre de 2003). Sentencia del Caso Bulacio vs Argentina.

OEA. CorteIDH. (25 de Noviembre de 2003). Sentencia del Caso Myrna Mack Chang vs Guatemala.

OEA. CorteIDH. (29 de Abril de 2004). Sentencia del Caso masacre Plan de Sánchez vs Guatemala.

OEA. CorteIDH. (5 de Julio de 2004). Sentencia del Caso 19 comerciantes vs Colombia.

OEA. CorteIDH. (7 de Septiembre de 2004). Sentencia del Caso Tibi vs Ecuador.

OEA. CorteIDH. (15 de Junio de 2005). Sentencia del Caso de la comunidad Moiwana vs Suriname.

OEA. CorteIDH. (17 de Junio de 2005). Sentencia del Caso comunidad indígena Yakye Axa vs Paraguay.

OEA. CorteIDH. (31 de Enero de 2006). Sentencia del Caso de la masacre de Pueblo Bello vs Colombia.

OEA. CorteIDH. (29 de Marzo de 2006). Sentencia del Caso Comunidad Indígena Sawhoyamaxa vs Paraguay.

OEA. CorteIDH. (4 de Julio de 2006). Sentencia del Caso Ximenes Lopes vs Brasil. 
OEA. CorteIDH. (5 de Julio de 2006). Sentencia del Caso Montero Aranguren y otros (Retén de Catia) vs Venezuela.

OEA. CorteIDH. (19 de Septiembre de 2006). Sentencia del Caso Claude Reyes y otros vs Chile.

OEA. CorteIDH. (21 de Septiembre de 2006). Sentencia del Caso Servellón García y otros vs Honduras.

OEA. CorteIDH. (26 de Septiembre de 2006). Sentencia del Caso Vargas Areco vs Paraguay.

OEA. CorteIDH. (26 de Septiembre de 2006). Sentencia del Caso Almonacid Arellano y otros vs Chile.

OEA. CorteIDH. (25 de Noviembre de 2006). Sentencia del Caso del Penal Miguel Castro Castro vs Perú.

OEA. CorteIDH. (26 de Noviembre de 2006). Sentencia del Caso La Cantuta vs Perú.

OEA. CorteIDH. (11 de Mayo de 2007). Sentencia del Caso de la masacre de La Rochela vs Colombia.

OEA. CorteIDH. (4 de Julio de 2007). Sentencia del Caso Zambrano Vélez y otros vs Ecuador.

OEA. CorteIDH. (10 de Julio de 2007). Sentencia del Caso Cantoral Huamaní y García Santa Cruz vs Perú.

OEA. CorteIDH. (2 de Agosto de 2008). Sentencia del Caso del Penal Miguel Castro vs Perú.

OEA. CorteIDH. (7 de Julio de 2009). Sentencia del Caso Valle Jaramillo y otros vs Colombia.

OEA. CorteIDH. (30 de Junio de 2009). Sentencia del Caso Reverón Trujillo vs Venezuela.

OEA. CorteIDH. (3 de Julio de 2009). Sentencia del Caso comunidad indígena Yakye Axa vs Paraguay.

OEA. CorteIDH. (2 de Noviembre de 2009). Sentencia de la Masacre de las Dos Erres vs Guatemala.

OEA. CorteIDH. (16 de Noviembre de 2009). Sentencia del Caso González y otros ("Campo Algodonero") vs México.

OEA. CorteIDH. (24 de Agosto de 2010). Sentencia del Caso comunidad indígena Xákmok Kásek vs Paraguay.

OEA. CorteIDH. (9 de Mayo de 2011). Sentencia del Caso Vera y otra vs Ecuador.

OEA. CorteIDH. (15 de Mayo de 2011). Sentencia del Caso Rosendo Cantú y otra vs México.

OEA. CorteIDH. (5 de Julio de 2011). Sentencia del Caso Mejía Idrovo vs Ecuador.

OEA. CorteIDH. (26 de Agosto de 2011). Sentencia del Caso Torres Millacura y otros vs Argentina. 
OEA. CorteIDH. (1 de Septiembre de 2011). Sentencia del Caso López Mendoza vs Venezuela.

OEA. CorteIDH. (27 de Febrero de 2012). Sentencia del Caso González Medina y familiares vs República Dominicana.

OEA. CorteIDH. (27 de Abril de 2012). Sentencia del Caso Fornerón e hija vs Argentina.

OEA. CorteIDH. (27 de Junio de 2012). Sentencia del Caso pueblo indígena Kichwa de Sarayaku vs Ecuador.

OEA. CorteIDH. (31 de Agosto de 2012). Sentencia del caso Furlán vs Argentina.

OEA. CorteIDH. (3 de Septiembre de 2012). Sentencia del Caso Vélez Restrepo y familiares vs Colombia.

OEA. CorteIDH. (21 de Noviembre de 2012). Sentencia del Caso Atala Riffo y niñas vs Chile.

OEA. CorteIDH. (28 de Noviembre de 2012). Sentencia del Caso Artavia Murillo y otros ("fecundación in vitro") vs Costa Rica.

OEA. CorteIDH. (20 de Noviembre de 2013). Sentencia del Caso de las comunidades afrodescendientes desplazadas de la cuenca del río Cacarica (operación génesis) vs Colombia.

OEA. CorteIDH. (26 de Noviembre de 2013). Sentencia del caso García Cruz y Sánchez Silvestre vs Estados Unidos Mexicanos.

OEA. CorteIDH. (19 de Agosto de 2013). Sentencia del Caso massacre de Santo Domingo vs Colombia.

OEA. CorteIDH. (30 de Enero de 2014). Sentencia del Caso Liakat Ali Alibux vs Suriname.

OEA. CorteIDH. (17 de Abril de 2015). Sentencia del Caso Cruz Sánchez y otros vs Perú.

OEA. CorteIDH. (23 de Junio de 2015). Sentencia del Caso Espinoza Gonzáles vs Perú.

República de Colombia. Consejo de Estado. Sala de lo Contencioso Administrativo. Sección Tercera. (Octubre 19 de 2007). Sentencia 05001-23-31-000-1998-02290-01(29273) A. [MP: Enrique Gil Botero].

República de Colombia. Consejo de Estado. Sala de lo Contencioso Administrativo. Sección Tercera. (Enero 29 de 2009). Sentencia 76001-23-31-000-1996-02530-01(16975). [MP: Mauricio Fajardo Gómez].

República de Colombia. Consejo de Estado. Sala de lo Contencioso Administrativo. Sección Tercera. (Mayo 13 de 2009). Sentencia 47001-23-31-000-1993-03405-01(16469). [MP: Myriam Guerrero de Escobar]. 
República de Colombia. Consejo de Estado. Sala de lo Contencioso Administrativo. Sección Tercera. (Febrero 18 de 2010). Sentencia 20001-23-31-000-1997-03529-01(18274). [MP: Enrique Gil Botero].

República de Colombia. Consejo de Estado. Sala de lo Contencioso Administrativo. Sección Tercera. (Febrero 18 de 2010). Sentencia 20001-23-31-000-1998-03713-01(18436). [MP: Mauricio Fajardo Gómez].

República de Colombia. Consejo de Estado. Sala de lo Contencioso Administrativo. Sección Tercera. (Marzo 3 de 2010). Sentencia 25000-23-26-000-2008-00192-01(37160). [MP: Mauricio Fajardo Gómez].

República de Colombia. Consejo de Estado. Sala de lo Contencioso Administrativo. Sección Tercera. (Mayo 4 de 2011). Sentencia 76001-23-25-000-1996-02231-01(19355)-22231, 22289 y 22528Acumulados). [MP: Enrique Gil Botero].

República de Colombia. Consejo de Estado. Sala de lo Contencioso Administrativo. Sección Tercera. (Agosto 29 de 2012). Sentencia 17001-23-31-000-2001-00216-01(24335). [MP: Stella Conto Diaz del Castillo].

República de Colombia. Consejo de Estado. Sala de lo Contencioso Administrativo. Sección Tercera. (Junio 20 de 2013). Sentencia 54001-23-31-000-1996-09250-01(23603). [MP: Jaime Orlando Santofimio Gamboa].

República de Colombia. Consejo de Estado. Sala de lo Contencioso Administrativo. Sección Tercera. (Mayo 8 de 2013). Sentencia 25000-23-26-000-2000-01293-01(27522). [MP: Olga Mélida Valle de la Hoz].

República de Colombia. Consejo de Estado. Sala de lo Contencioso Administrativo. Sección Tercera. (Octubre 9 de 2014). Sentencia 20001-23-31-000-2005-01640-01(40411). [MP: Ramiro de Jesús Pazos Guerrero].

República de Colombia. Consejo de Estado. Sala de lo Contencioso Administrativo. Sección Tercera. (9 de Noviembre de 2014). Sentencia 07001-23-31-000-2002-00228-01(29033). [MP: Ramiro de Jesús Pazos Guerrero].

República de Colombia. Consejo de Estado. Sala de lo Contencioso Administrativo. Sección Tercera. (Marzo 12 de 2015). Sentencia 52001-23-31-000-1999-00838-01(30413). [MP: Hernán Andrade Rincón]. 